\title{
El contenido de la negociación colectiva de los funcionarios públicos en la Administración Local
}

\author{
Remedios Roqueta Buj \\ Catedrática de Derecho del Trabajo y de la Seguridad Social \\ Universidad de las Islas Baleares
}

\begin{abstract}
Sumario: 1. INTRODUCCIÓN. 2. LAS MATERIAS EXCLUIDAS DE LA CONSULTA Y DE LA NEGOCIACIÓN. 3. LAS MATERIAS OBJETO DE CONSULTA. 4. LAS MATERIAS OBJETO DE NEGOCIACIÓN. 4.1. Materias organizativas con incidencia en el ámbito funcionarial. a) La clasificación de puestos de trabajo. b) Los Planes de Empleo. c) La preparación y diseño de los planes de oferta de empleo público. d) Los sistemas de ingreso, provisión y promoción profesional de los funcionarios públicos. 4.2. Materias de índole retributiva. 4.3. Materias de índole funcionarial. 4.4. Materias de índole sindical. 4.5. Materias relativas a la salud laboral. 4.6. Materias relativas a la Seguridad Social y de índole asistencial. 5. A MODO DE CONCLUSIÓN.
\end{abstract}

\section{INTRODUCCIÓN}

El objetivo marcado para el presente trabajo no es otro que el de delimitar el área de desenvolvimiento de la actividad negocial de las Entidades Locales (EELL) y sus funcionarios públicos. A tales efectos, debe partirse de lo dispuesto en los artículos 32 y 34 de la de la Ley 9/1987, de 12 de junio, de Órganos de representación, determinación de las condiciones de trabajo y participación del personal al servicio de las Administraciones Públicas (LORAP) ${ }^{1}$.

\footnotetext{
${ }^{1}$ Para un estudio detallado del Capítulo III de la LORAP ver, por todos, T. SALA Franco y R. RoQueta Buj, Los derechos sindicales de los funcionarios públicos, Valencia, 1995, pp. 223 y ss.; R. RoQueta Bus, La negociación colectiva en la función pública, Valencia, 1996, «Las especialidades aplicativas de la Ley 7/1990 en el ámbito de las Instituciones Sanitarias Públicas», en AA.VV., Aspectos del Régimen Jurídico de la Sanidad Pública, IVESP, Valencia, 1995, pp. 175 y ss., «Los órganos de representación unitaria y la negociación colectiva en la Función Pública», en AA.VV., III Curso de Derecho Público Autonómico, Seminario de Función Pública Valenciana, Generalitat Valenciana, Valencia, 1996, pp. 141 y ss., «El contenido de la negociación colectiva en materia de clasificación de puestos de trabajo y de retribuciones de los funcionarios locales», Poder Judicial, n. ${ }^{\circ} 43-44,1996$, pp. 305 y ss., «La negociación colectiva en la función pública local», REALA, n. ${ }^{\circ}$ 279,1999 , pp. 69 y ss., «Los acuerdos mixtos para los trabajadores y funcionarios de las Entidades Locales», REALA, n. ${ }^{\circ} 280-281,1999$, pp. 291 y ss., «La negociación colectiva en la función pública», Temas Laborales, en prensa, y «La negociación de los funcionarios locales», en AA.VV., Tratado de Derecho Municipal II, Dirigido por Muñoz Machado, Madrid, 2003, pp. 2493 y ss.; S. DeL $\mathrm{SAZ}$, Contrato laboral y función pública (del contrato laboral para trabajos manuales al contrato blindado de alta dirección), Madrid, 1995; J. MAURI MAJOS, «Problemas de representación sindical y la negociación colectiva en la función pública. Convergencias y divergencias con el empleo pri-
} 
Los antecitados preceptos distinguen tres tipos de materias a efectos de negociación: a) Materias excluidas de la consulta y de la negociación (art. 34.1); b) Materias objeto de consulta (art. 34.2); y c) Materias objeto de negociación (art. 32).

\section{LAS MATERIAS EXCLUIDAS DE LA CONSULTA Y DE LA NEGOCIACIÓN}

De acuerdo con el apartado primero del artículo 34 de la LORAP, «quedan excluidas de la obligatoriedad de la negociación, en su caso, las decisiones de las Administraciones Públicas que afecten a sus potestades de organización, al ejercicio del derecho de los ciudadanos ante los funcio-

vado», $D A$, n. $^{\circ} 214-242,1995$, pp. 164 y ss.; J.J. FernÁNDEZ DomíngueZ y S. Rodríguez EsCANCIANo, La Negociación Colectiva de los Funcionarios Públicos, Barcelona, 1996; A. Palomar Olmeda, Derecho de la Función Pública, Régimen jurídico de los funcionarios públicos, Madrid, 2001, pp. 606 y ss.; R. Manzana Laguarda, Derechos y deberes de los funcionarios públicos, Valencia, 1996, pp. 253 y ss.; S. Del Rey Guanter y M. LuQue Parra, «Criterios jurisprudenciales recientes sobre la negociación colectiva de los funcionarios públicos», $R L, \mathrm{n}^{\circ}{ }^{\circ} 4,1997, \mathrm{pp}$. 12 y ss.; M. RodRíGUEZ PIÑERO, «Ley y negociación colectiva en la función pública», $R L$, II/1997, pp. 9 y ss.; Ma.J. RodRíGUez Ramos, El estatuto de los funcionarios públicos, Su convergencia con el Estatuto de los Trabajadores, Granada, 1997, pp. 390 y ss.; M. SANCHÉZ Moron, Derecho de la función pública, 1997, pp. 234 y ss.; F. VALDES DAL-RE, «Los derechos de negociación colectiva y de huelga de los funcionarios públicos en el ordenamiento jurídico español: una aproximación», REDT, n. ${ }^{\circ} 86,1997$, pp. 837 y ss.; G. Dieguez Cuervo, «Legitimación procesal del sindicato de funcionarios de una mesa de negociación», REDT, n. ${ }^{\circ}$ 91, 1998, pp. 809 y ss.; P.A. MARTíN PÉREZ, «La negociación colectiva en la función pública local», A.A., n. ${ }^{\circ} 38,1999$, pp. 1037 y ss.; A. MARTíNEZ MARÍN, «El funcionario y la negociación colectiva. Redefinición dogmática de la naturaleza jurídica de la relación funcionarial», en AA.VV., El Estatuto de la Función Pública, ¿La reforma adecuada?, Actas del II Congreso sobre la Función Pública, Sevilla, 1999, pp. 351 y ss.; I.A. RodRíguez CARDO, «La negociación colectiva de los funcionarios públicos», Revista de Trabajo y Seguridad Social, Estudios Financieros, n. ${ }^{\circ}$ 200, 1999, pp. 51 y ss.; A. SANChÉz RodríGuez, «E1 derecho a la negociación colectiva en la Función Pública», en AA.VV., El Estatuto de la Función Pública, ¿La reforma adecuada?, Actas del II Congreso sobre la Función Pública, Sevilla, 1999, pp. 161 y ss.; A. Desdentado Bonete y E. Desdentado Daroca, «El sistema normativo de la relación de servicio del personal estatutario en las Instituciones Sanitarias de la Seguridad Social», Centro de Documentación Judicial, Consejo General del Poder Judicial, Manual de Formación Continua, n. ${ }^{\circ} 11,2000$, pp. 75 y ss.; I. MARín ALONSo, «El Derecho del Trabajo y la negociación colectiva de los empleados públicos», en AA.VV., Las relaciones laborales en las Administraciones Públicas, Volumen II, XI Congreso Nacional de Derecho del Trabajo y de la Seguridad Social, Madrid, 2001, pp. 251 y ss.; T. SALA FranCo, «La negociación colectiva en el empleo público», en AA.VV., Cuestiones actuales sobre la negociación colectiva, XIV Jornadas de Estudios sobre la negociación colectiva, Madrid, 2001, pp. 125 y ss.; Mª.N. MARTínez GAYOSO, El derecho a la negociación colectiva de los funcionarios públicos en la Constitución, Zarautz (Gipuzkoa), 2002, y Las comisiones de seguimiento de pactos y acuerdos en la función pública, Basauri (Bizkaia), 2002; y J. LANDA ZAPIRAIN y otros, La negociación de las condiciones de trabajo de los empleados públicos al servicio de las Administraciones Públicas Vascas, Madrid, 2003. Además, debe tenerse en cuenta la abundantísima bibliografía que se cita en R. RoQueTA BuJ, La negociación colectiva..., cit. 
narios públicos y al procedimiento de formación de los actos y disposiciones administrativas».

La cuestión central consiste en determinar el alcance de la expresión «potestades de organización». Es decir, dilucidar, si comprende sólo las decisiones adoptadas en materia de estructura administrativa interna o también las adoptadas en relación con la organización de la función pública. A este respecto es necesario tener en cuenta que el diseño de la función pública en las diferentes Administraciones Públicas (AAPP) supone la existencia de un proceso complejo en el que es inexcusable distinguir varias fases de distinta trascendencia ${ }^{2}: 1^{\text {a }}$ ) La determinación de la estructura orgánica interna de las diferentes Administraciones, que supone el establecimiento o configuración de la organización, y que se traduce en la posibilidad de determinar concretamente la estructura interna y el detalle de los diferentes órganos administrativos, así como la concreción de sus funciones; $2^{\mathrm{a}}$ ) la organización de la función pública que se desarrolla fundamentalmente a través de las plantillas orgánicas, las relaciones de puestos de trabajo (RPT), los catálogos de puestos de trabajo, la oferta de empleo público, etc.

A favor de una interpretación no extensiva del concepto que nos ocupa se pueden aducir varios argumentos. Así, en primer lugar, la interpretación sistemática de los artículos 34 y 32.k) de la LORAP. Como se sabe la cláusula general que recoge este último precepto constituye una trascripción casi literal de las prescripciones que sobre el contenido de la negociación colectiva laboral recoge el artículo 85.1 del Real Decreto Legislativo 1/1995, de 24 de marzo, por el que se aprueba el Texto Refundido de la Ley del Estatuto de los Trabajadores (ET). Y, aunque la cercanía terminológica no puede ocultar que el significado de ambos preceptos es diferente, ya que el contexto jurídico-positivo en el que se insertan es distinto ${ }^{3}$, lo cierto es que el artículo 85.1 del ET sirve de criterio hermenéutico del artículo 32.k) de la LORAP. Y a este respecto conviene notar que aquél ha sido interpretado en un sentido amplio como comprensivo del poder empresarial de organización del trabajo. Pero es que, además, varias de las materias específicamente contempladas en el artículo 32 de la LORAP son más organizativas que funcionariales. Tal sucede con la clasificación de puestos de trabajo, la oferta de empleo público y los sistemas de ingre-

\footnotetext{
2 Ver Fondevilla Antolin, «Nuevos aspectos sobre la naturaleza de las estructuras orgánicas y relaciones de puestos de trabajo: jurisprudencia reciente», $R V A P$, n. ${ }^{\circ} 28,1990$, pp. 61 y ss.

${ }^{3}$ S. Del Rey Guanter, Comentarios a la Ley de Órganos de Representación, Determinación de las Condiciones de Trabajo y Participación del Personal al Servicio de las Administraciones Públicas, Madrid, 1988, p. 212.
} 
so, provisión y promoción profesional de los funcionarios. Se trata de materias organizativas con incidencia en el ámbito funcionarial, cuya inclusión en la esfera de lo negociable pone de manifiesto que la expresión «potestades de organización» es empleada en su acepción más estricta. De este modo, no procede la negociación cuando, por ejemplo, se aprueba el Estatuto de un Organismo Autónomo ${ }^{4}$, se realiza una reestructuración organizativa en un Organismo Autónomo ${ }^{5}$, o se resuelve sobre el sistema de gestión de un servicio público, acordando que la gestión se verifique de manera indirecta por medio de una empresa concesionaria ${ }^{6}$. Ahora bien, si con el pretexto del ejercicio de la potestad de autoorganización se regulan o se modifican las remuneraciones o la jornada de trabajo de los funcionarios, por poner un ejemplo, en tal caso se impone la necesidad de aplicar el artículo 32 de la LORAP, sometiendo tales extremos a la obligatoria negociación 7 .

\section{LAS MATERIAS OBJETO DE CONSULTA}

De acuerdo con lo dispuesto en el apartado segundo del artículo 34 de la LORAP, «cuando las consecuencias de las decisiones de las Administraciones Públicas que afecten a sus potestades de organización puedan tener repercusión sobre las condiciones de trabajo de los funcionarios públicos, procederá la consulta a las Organizaciones Sindicales y Sindicatos a que hacen referencia los artículos 30 y 31.2 de la presente Ley». Así, procederá la consulta a los sindicatos en la mesa de negociación correspondiente cuando las decisiones de las EELL excedan del ámbito puramente doméstico de la organización administrativa y vayan a afectar de una forma «directa» e «inmediata» sobre los intereses del colectivo funcionarial ${ }^{8}$. Pero esta delimitación no agota todos los supuestos comprendidos en el antecitado precepto, ya que en base a lo por él formulado

\footnotetext{
${ }^{4}$ STS de 4 de marzo de $2003(\mathrm{RJ} / 2540)$.

${ }^{5}$ STS de 19 de octubre de 1999 (RJ/9367).

${ }^{6}$ STS de 25 de marzo de 2002 (RJ/3632). En sentido contrario, la STSJ de Asturias de 30 de enero de 1998 (RJCA/271). Tampoco procede la negociación cuando se establece el procedimiento para la elección del Jefe de Seminario Didáctico en los Centros de Enseñanza Secundaria [STS de 28 de abril de 2000 (RJ/4831)], o cuando se permite la integración voluntaria en el personal estatutario de la Seguridad Social de los funcionarios que ocupaban plazas de ese carácter en el Servicio Valenciano de Salud [STS de 9 de febrero de 2004 (RJ/1400)].

7 STS de 18 de febrero de 2003 (RJ/231) y STSJ de Baleares de 10 de junio de 2003 (JUR/247257). En cambio, la STS de 4 de febrero de 2004 (RJ/886) sostiene que en tales casos procede la consulta obligatoria en base a lo dispuesto en el artículo 34.2 de la LORAP.
}

${ }^{8}$ SSTS de 5 de mayo de 1998 (RJ/4723) y 25 de marzo de 2002 (RJ/3632). 
no es necesario que las consecuencias de las decisiones adoptadas a nivel orgánico en la relación de servicio sean de una nitidez indiscutible. Basta, según la redacción literal del precepto, con que tales decisiones «puedan» tener repercusión sobre las condiciones de trabajo de los funcionarios. Y esto es lo que sucede, por ejemplo, cuando se organiza jerárquicamente el Departamento Foral de Urbanismo y no se prevén los Negociados, pues esta omisión repercutirá sobre los puestos de trabajo existentes y, por eso, sobre la posible promoción de los funcionarios a las jefaturas de dichas unidades ${ }^{9}$; o cuando se acuerda que la gestión de un servicio público se verifique por medio de una empresa adjudicataria, pues los funcionarios destinados en dicho servicio tendrán que ser adscritos a otros puestos de trabajo de la organización local, lo que entra dentro del concepto de asignación de efectivos que es una de las formas de provisión de los puestos de trabajo ${ }^{10}$. Por lo demás, como consecuencia de tales decisiones, será preciso modificar las condiciones de trabajo de los funcionarios públicos; decisiones que tendrán que ser negociadas colectivamente ${ }^{11}$. Pero éstas son cuestiones que se plantearán en el futuro, una vez se haya llevado a cabo la reestructuración orgánica o la adjudicación del servicio a la empresa adjudicataria.

Por último, se ha dicho que la organización de la función pública se incluye en la esfera de lo negociable. Sin embargo, esta afirmación ha de ser matizada en relación con la plantilla. En principio, ésta se presenta como una típica manifestación de la potestad organizatoria de cada Entidad Local, a confeccionar anualmente, a través del Presupuesto ${ }^{12}$; instrumento organizatorio que no se incluye entre las materias que, por imperativo del artículo 32 de la LORAP, están sujetas a negociación obligatoria $^{13}$. En efecto, la noción de «clasificación de puestos de traba-

9 En sentido contrario, la STS de 5 de mayo de 1998 (RJ/4723).

10 En sentido contrario, la STS de 25 de marzo de 2002 (RJ/3632).

También procede la consulta sindical cuando se regula el Servicio de Guardia por el Consejo General del Poder Judicial [STS de 26 de mayo de 1998 (RJ/5906)]; se fijan las condiciones y responsabilidades del personal al servicio de la Comunidad Autónoma durante la campaña de lucha contra incendios forestales [STS de 6 de marzo de 1997 (RJ/2165)]; o, en fin, cuando se alude a la adscripción de los médicos especialistas jefes y ayudantes de cupo a los centros hospitalarios [STSJ de Navarra de 5 de abril de 2001 (JUR/171677)].

11 STS de 25 de marzo de $2002(\mathrm{RJ} / 3632)$.

12 Cfr. artículos 90.1 de la Ley 7/1985, de 2 de abril, reguladora de las Bases del Régimen Local (LBRL), y 126.1 del Real Decreto Legislativo 781/1986, de 18 de abril, por el que se aprueba el Texto Refundido de las disposiciones legales vigentes en materia de Régimen Local (TRRL).

13 En este sentido, la STS de 16 de noviembre de 2001 (RJ/9752) afirma que la plantilla orgánica municipal constituye un «instrumento organizatorio que no se incluye entre las materias que, por 
jo» que emplea la letra d) del antecitado precepto responde al estricto sentido que deriva del artículo 15 de la Ley 30/1984, de 2 de agosto, de Medidas para la Reforma de la Función Pública (LMRFP), que no comprende lo relativo a la organización y al número de puestos de trabajo de que se doten las AA.PP. para prestar los servicios públicos. Por otra parte, y por lo que respecta a la referencia a «los planes de oferta de empleo público» del artículo 32.c) de la LORAP, hay que señalar que la plantilla y la oferta de empleo público son instrumentos de ordenación de personal diferentes. Aunque haya que reconocer cierta relación entre los mismos, que exige que haya correspondencia entre ellos, de modo que su falta podría tener consecuencias en la validez de la oferta, esto no quiere decir que por esa relación, inexcusablemente, la plantilla deba someterse a la negociación con los sindicatos en la mesa de negociación correspondiente, puesto que en la confección de la plantilla preponderan los aspectos organizatorios y presupuestarios propios de la potestad organizatoria de las EELL.

Ahora bien, si con posterioridad se modifica la plantilla, con la consiguiente supresión o modificación de puestos de trabajo que se encuentran cubiertos por funcionarios públicos, es claro que, al menos, tal decisión afecta al apartado $\mathrm{k}$ ) del artículo 32 de la LORAP, por lo que será preceptiva la negociación ${ }^{14}$, y ello con independencia del mayor o menor alcance (en razón al número de puestos de trabajo afectados) que pueda tener dicha modificación ${ }^{15}$. Y de encontrarse vacantes los puestos de trabajo amortizados, en la medida que ello puede repercutir sobre la promoción

imperativo del art. 32 de la Ley 9/1987, están sujetas a la negociación sindical a través de la Mesa, sino que ha de situarse entre las que, en aplicación del art. 34.2 de esa Ley, únicamente requieren el sometimiento a informe de las Organizaciones sindicales a que aluden los arts. 30 y 31.2 de esta Ley». En parecidos términos se expresan la STS de 5 de mayo de 1998 (RJ/4723), la STSJ de Andalucía de 7 de febrero de 2001 (JUR/298183) y la STSJ de Canarias de 24 de abril de 2002 (JUR/250248). Cfr. la STS de 14 de abril de 2000 (RJ/4823).

${ }^{14}$ En el mismo sentido, las SSTS de 16 de enero de 2004 (RJ/428), 19 de enero de 2004 (RJ/558), 6 de febrero de 2004 (RJ/972) y 11 de mayo de 2004 (RJ/3296); y la STSJ de Navarra de 24 de julio de 2003 (JUR/220153). En sentido contrario, las SSTS de 5 de mayo de 1998 (RJ/4723) y 22 de diciembre de 2001 (RJ/8190, 2002). Por su parte, la STSJ de la Comunidad Valenciana de 14 de abril de 1998 (RJCA/1291) afirma que cuando se amortizan puestos de trabajo, como ello afecta a las condiciones de trabajo en la función pública, procede la consulta a las organizaciones sindicales que impone el artículo 34.2 de la LORAP. En el mismo sentido, la STSJ de Baleares de 8 de marzo de 2002 (JUR/127982) y la STSJ de la Comunidad Valenciana de 28 de enero de 2003 (JUR/22516, 2004), si bien esta última solo en el supuesto de que los puestos de trabajo amortizados no se encuentren vacantes.

15 SSTS de 16 de enero de 2004 (RJ/428), 19 de enero de 2004 (RJ/558) y 6 de febrero de 2004 (RJ/972). 
de los funcionarios de la Corporación Local, será precisa la consulta que establece el artículo 34.2 de la LORAP.

\section{LAS MATERIAS OBJETO DE NEGOCIACIÓN}

De acuerdo con lo preceptuado en el artículo 32 de la LORAP, «serán objeto de negociación en su ámbito respectivo y en relación con las competencias de cada Administración Pública las materias siguientes: a) El incremento de retribuciones de los funcionarios y del personal estatutario de las Administraciones Públicas que proceda incluir en el Proyecto de Presupuestos Generales del Estado de cada año, así como el incremento de las demás retribuciones a establecer, para su respectivo personal, en los proyectos normativos correspondientes de ámbito autonómico y local. b) La determinación y aplicación de las retribuciones de los funcionarios públicos. c) La preparación y diseño de los planes de oferta de empleo público. d) La clasificación de puestos de trabajo. e) La determinación de los programas y fondos para la acción de promoción interna, formación y perfeccionamiento. f) La determinación de las prestaciones y pensiones de las clases pasivas y, en general, todas aquellas materias que afecten, de algún modo, a la mejora de las condiciones de vida de los funcionarios jubilados. g) Los sistemas de ingreso, provisión y promoción profesional de los funcionarios públicos. h) Las propuestas sobre derechos sindicales y de participación. i) Medidas sobre salud laboral. j) Todas aquellas materias que afecten, de algún modo, al acceso a la Función Pública, Carrera administrativa, retribuciones y Seguridad Social, o a las condiciones de trabajo de los funcionarios públicos y cuya regulación exija norma con rango de Ley. k) Las materias de índole económica, de prestación de servicios, sindical, asistencial, y en general cuantas otras afecten a las condiciones de trabajo y al ámbito de relaciones de los funcionarios públicos y sus Organizaciones Sindicales con la Administración».

Una exacta comprensión del alcance y límites del ámbito objetivo de la negociación colectiva de los funcionarios locales requiere efectuar las siguientes precisiones y aclaraciones complementarias:

$1^{\text {a }) ~ L a ~ f o r m a ~ i m p e r a t i v a ~ e m p l e a d a ~ p o r ~ e l ~ a r t i ́ c u l o ~} 32$ de la LORAP («serán objeto de negociación en su ámbito respectivo y en relación con las competencias de cada Administración Pública las materias siguientes...»), determina el carácter estrictamente obligatorio de la negociación previa, se logre o no un consenso y requiera o no el Acuerdo alcanzado la aprobación expresa y formal del órgano de gobierno de la correspondien- 
te Administración ${ }^{16}$. A mayor abundamiento, el artículo 37.2 de la LORAP condiciona la potestad de los órganos de gobierno de las Administraciones Públicas de regular unilateralmente las condiciones de trabajo de los funcionarios públicos a que no se haya producido acuerdo en la negociación o el Acuerdo alcanzado en la Mesa de negociación no haya sido aprobado expresa y formalmente por el órgano de gobierno de la correspondiente Administración, lo que «presupone por definición la existencia previa de una negociación, real o intentada $\rangle^{17}$. De todo ello se desprende la existencia de «una reserva desde la Ley para la negociación respecto a las materias enunciadas» en el artículo 32 de la LORAP, con la consiguiente limitación a la posibilidad de que su ordenación pueda realizarse unilateralmente por la Administración sin haberse intentado previamente su negociación ${ }^{18}$. Ahora bien, el deber de negociar y de hacerlo, además, de acuerdo con el principio de buena fe no obliga a las partes a llegar a un acuerdo, y prueba de ello es la expresa previsión legal de mecanismos para suplir los fracasos de la autonomía colectiva ${ }^{19}$.

$2^{\text {a }) ~ L a ~ i n c l u s i o ́ n ~ d e ~ l a s ~ m a t e r i a s ~ q u e ~ s e n ̃ a l a ~ e l ~ a r t i ́ c u l o ~} 32$ de la LORAP en el ámbito de la negociación colectiva de los funcionarios locales está, sin embargo, condicionada por un factor fundamental, a saber: el reparto de competencias normativas en materia funcionarial entre el Estado, las Comunidades Autónomas (CCAA) y las EELL, operado por el bloque de constitucionalidad. En efecto, tales materias serán objeto de negociación, como subraya el propio artículo 32 de la LORAP, «en su ámbito respectivo y en relación con las competencias de cada Administración Pública ${ }^{20}$. La vinculación funcional entre las Mesas generales de negociación de la Administración del Estado, de las CCAA y de las EELL es un reflejo o

\footnotetext{
16 SSTS de 10 de noviembre de 1994 (RJ/9040), 18 de octubre de 1995 (RJ/7566), 29 de mayo de 1997 (RJ/4534) y 14 de abril de $2000(\mathrm{RJ} / 4823)$.

17 STS de 10 de noviembre de 1994 (RJ/9040).

18 STS de 16 de noviembre de 1995 (RJ/8791).

19 SSTS de 13 de abril de 1998 (RJ/4614, 4615, 4616, 4617, 4618, 4619 y 4620), 4 de mayo de 1998 (RJ/4835), 9 de febrero de 1999 (RJ/2068), 1 de marzo de 1999 (RJ/2736), 26 de marzo de 1999 (RJ/3736), 30 de marzo de 1999 (RJ/3268) y 17 de febrero de 2003 (RJ/2112); STSJ del País Vasco de 22 de diciembre de 2000 (JUR/255549, 2001); y STSJ de Baleares de 13 de junio de 2003 (JUR/247577).

${ }^{20}$ La competencia material de la Administración Pública que negocia es presupuesto de la negociación colectiva prevista en la LORAP. Así lo ponen de manifiesto, entre otras, las SSTS de 16 de noviembre de 1994 (RJ/555, 1995), 16 de junio de 1995 ( $A L$ 16/1996), 7 de noviembre de 1995 (RJ/8173), 4 de diciembre de 1995 (RJ/1564, 1996), 30 de junio de 1997 (RJ/6138) y 22 de diciembre de 1997 (RJ/315, 1998); STSJ de Asturias de 18 de mayo de 1998 (RJCA/1758); STSJ de Andalucía de 8 de junio de 1998 (RJCA/2314); R. Manzana Laguarda, R., Derechos y Deberes..., cit., pp. 273 y ss.; y P.A. MARTín PÉREZ, «La negociación colectiva...», cit., pp. 1064 y 1065.
} 
trasunto de la articulación funcional que se da entre las competencias normativas del Estado, las CCAA y las EELL ${ }^{21}$. Por consiguiente, hay que efectuar un recorrido por la legalidad, básica y no básica ${ }^{22}$, reguladora de la función pública local para ver qué materias son competencia del Estado, cuáles de las CCAA y cuáles otras de las propias EELL ${ }^{23}$. En este sentido, habrán de tenerse presentes la Ley de Funcionarios Civiles del Estado aprobada por Decreto 315/1964, de 7 de febrero (LFCE), la LMRFP, la Ley 7/1985, de 2 de abril, reguladora de las Bases del Régimen Local (LBRL), el Real Decreto Legislativo 781/1986, de 18 de abril, por el que se aprueba el Texto Refundido de las disposiciones legales vigentes en materia de Régimen Local (TRRL) y, en su caso, la normativa autonómi$\mathrm{ca}^{24}$. Aquellas materias que quedan comprendidas en la esfera de la competencia normativa del Estado (Cortes Generales, Gobierno o Ministro para las Administraciones Públicas) habrán de negociarse en el seno de la Mesa general de la Administración del Estado, las que sean competencia de las CCAA en la Mesa general de negociación de la respectiva Comunidad Autónoma y las que entren dentro del poder normativo local en las Mesas de negociación que se constituyan en cada Entidad Local. De este modo, las materias cuya regulación corresponda al Estado o a las CCAA quedan fuera de la órbita de la autonomía colectiva local ${ }^{25}$. A lo que debe añadirse, como tiene declarado el Tribunal Supremo, que «las caracterís-

${ }^{21}$ En este sentido, S. Del Rey Guanter, Comentarios..., cit., p. 191; A. Lazaro Moreno, «La negociación colectiva y el régimen estatutario de los funcionarios públicos», El Consultor de los Ayuntamientos, n. ${ }^{\circ}$ 6, 1993, p. 844; M. RAZQUIN LIZARRAGA, «Funcionarios, bases y negociación colectiva (Comentarios a la STS de 30 de mayo de 1992)», RAP, n. ${ }^{\circ} 131,1993$, p. 227; P. GómEZ Caballero, Los Derechos Colectivos de los Funcionarios, Madrid, 1994, p. 303; T. Sala Franco T. y R. Roqueta Buj, Los derechos sindicales de los funcionarios públicos, Valencia, 1995, pp. 261 y ss.; y R. RoQueta BuJ, La negociación colectiva en la función pública, cit., pp. 262 y ss.

${ }^{22}$ SSTS de 4 de diciembre de 1995 (RJ/1564, 1996), 14 de octubre de 1996 (AL 179/1997) y 5 de diciembre de 1997 (RJ/307, 1998).

${ }^{23}$ Ver, por todas, las SSTS de 16 de noviembre de 1994 (RJ/555, 1995), 16 de junio de 1995 ( $A L$ 16/1996), 7 de noviembre de 1995 (RJ/8173), 4 de diciembre de 1995 (RJ/1564, 1996), 14 de octubre de 1996 (AL 179/1997), 10 de febrero de 1997 (RJ/1409) y 30 de junio de 1997 (RJ/6138).

${ }^{24}$ Sobre la normativa aplicable a la función pública local ver, por todos, A. SERRANo Pascual, El personal de las Entidades Locales, Análisis de su régimen juridico, El Consultor de los Ayuntamientos y de los Juzgados, Madrid, 1997, pp. 45 y ss.

${ }_{25}$ Por todas, las SSTS de 16 de noviembre de 1994 (RJ/555, 1995), 4 de diciembre de 1995 (RJ/1564, 1996), 10 de febrero y 30 de junio de 1997 (RJ/1409 y 6138), y 21 de noviembre de 1997 $(\mathrm{RJ} / 306,1998)$.

Ahora bien, no está prohibida la reproducción del contenido de las normas estatales o autonómicas en los Acuerdos y Pactos Locales. En este sentido se expresan, entre otras, las SSTSJ de Aragón, de 28 de noviembre de 2000 (JUR/93207, 2001); de Cantabria, de 8 de abril de 2002 (RJCA/773); y de Extremadura, de 18 de marzo de 2003 (JUR/123676). 
ticas de pormenorización, rigidez y uniformidad inherentes al régimen estatutario emanado de la legislación básica del Estado y, en su caso, de los órganos legislativos de las Comunidades Autónomas, no permiten que por analogía con el sistema de relaciones laborales $\{\ldots\}$, tal bloque legislativo sea identificable como plataforma de «mínimos», sobre la que pueda pivotar una constelación de unidades negociadoras pactando cada una a su libre albedrío, bajo el lema de que lo que no está prohibido por la ley debe presumirse que está permitido y puede ser objeto de regulación con arreglo al buen criterio de la Mesa de Negociación, refrendado por la respectiva Corporación Municipal» ${ }^{26}$. Es decir, en estas materias no tiene cabida una negociación colectiva local contraria o distinta a la norma estatal o autonómica, ni de mejora de éstas, siendo nulos los Acuerdos y Pactos que así procedan ${ }^{27}$. Por consiguiente, el poder negocial en el ámbito local es residual, pues sólo puede operar allí donde no han llegado ni el poder normativo estatal ni el autonómico.

A la luz de las consideraciones anteriores, procede abordar el análisis de la extensión a la que se ciñe el ámbito objetivo o contenido de la negociación colectiva en la función pública local, distinguiendo a tales efectos las siguientes materias: materias organizativas con incidencia en el ámbito funcionarial, materias de índole retributiva, funcionarial, sindical, y materias relativas a la salud laboral y a las prestaciones de la Seguridad Social o de índole asistencial.

\subsection{Materias organizativas con incidencia en el ámbito funcionarial}

La LORAP incluye en la esfera de lo negociable las materias organizativas con incidencia en el ámbito funcionarial que se señalan a continuación. Ahora bien, debe subrayarse que el que estas materias sean negociables no significa que las relaciones de puestos de trabajo, los catálogos de

\footnotetext{
${ }^{26}$ STS de 22 de octubre de 1993 (RJ/7544). En el mismo sentido, las SSTS de 5 de mayo de 1994 (RJ/4315), 16 de noviembre de 1994 (RJ/555, 1995), 16 de junio de 1995 (AL 16/1996), 30 de octubre de 1995 (RJ/7907), 7 de noviembre de 1995 (RJ/8173), 4 de diciembre de 1995 (RJ/1564, 1996), 18 de noviembre de 1996 (RJ/9749), 3 y 10 de febrero de 1997 (RJ/923 y 1409), 30 de junio de 1997 (RJ/6138), 21 de noviembre de 1997 (RJ/306, 1998), 5 de diciembre de 1997 (RJ/307, 1998), 22 de diciembre de 1997 (RJ/315, 1998), 20 de enero de 1998 (RJ/1419), 25 de junio de $1999(\mathrm{RJ} / 5511$ y 6451) y 27 de septiembre de 2000 (RJ/8597); STSJ de Canarias de 21 de mayo de 1999 (RJCA/1424); y STSJ de Castilla-La Mancha de 15 de septiembre de 1999 (RJCA/3197).

27 Por todas, las SSTS de 14 de octubre de 1996 (AL 179/1997) y 10 de febrero de 1997 (RJ/1409); y STSJ del País Vasco de 29 de noviembre de 1996 (A.A. a) 89/1997).
} 
puestos, los Planes de Empleo, la oferta de empleo público,... etc., en cuanto tales, hayan pasado a la esfera de la negociación colectiva. A la actividad negocial le corresponde establecer las reglas y criterios generales conforme a los cuales las EELL deberán elaborar tales instrumentos organizativos, configurándose como actividad preparatoria de la correspondiente decisión administrativa.

\section{a) La clasificación de puestos de trabajo}

El artículo 32.d) de la LORAP incluye, entre las materias que deben ser objeto de negociación, «la clasificación de puestos de trabajo». La clasificación de puestos de trabajo se plasma en las relaciones de puestos de trabajo (RPT) y, en su defecto, en los catálogos de puestos. Pues bien, siendo que la Ley admite la negociación sobre las características esenciales de los puestos de trabajo y que las RPT y catálogos de puestos constituyen los instrumentos básicos en esta materia, hay que entender que el tema referente a los mismos se incluye en la esfera de lo negociable ${ }^{28}$, y ello con independencia del mayor o menor número de puestos de trabajo afectados por la clasificación pues el artículo 32.d) de la LORAP no establece ninguna salvedad en función de esta circunstancia ${ }^{29}$. Ahora bien, como se ha dicho, el que esta materia sea negociable no significa que las RPT y los catálogos de puestos, en cuanto tales, hayan pasado a la esfera de la negociación colectiva. A la actividad negocial le corresponde establecer las normas y criterios generales conforme a los cuales las EELL deberán elaborar tales instrumentos organizativos ${ }^{30}$.

\footnotetext{
28 Así lo señalan en relación con la formación de las RPT, las SSTSJ de Canarias de 12 de marzo de 1998 (RJCA/821), 2 de febrero de 2001 (JUR/146566), 21 de mayo de 2001 (JUR/33198, 2002), 24 de abril de 2002 (JUR/250248) y 4 de junio de 2003 (JUR/14369, 2004); las SSTSJ del País Vasco de 14 de septiembre de 2000 (JUR/253313) y 8 de marzo de 2002 (JUR/150662); y la STSJ de Cataluña de 4 de mayo de 2004 (JUR/194311). Y a propósito de los catálogos de puestos, la STS de 14 de abril de 2000 (RJ/4823), la STSJ de Canarias de 12 de marzo de 1998 (RJCA/821) y la STSJ de Castilla-La Mancha de 20 de abril de 2002 (JUR/173545). Las SSTS de 5 de mayo de 1998 (RJ/4723) y 22 de diciembre de 2001 (RJ/8190, 2002), sin embargo, afirman que «la noción de clasificación de puestos de trabajo en el área de la función pública responde al estricto sentido que deriva del Capítulo VI de la Ley de Reforma de la Función Pública».

Sobre esta cuestión véanse, por todos, R. RoQueTA BuJ, La negociación colectiva en la función pública, cit., pp. 272 y ss., y «El contenido de la negociación colectiva...», cit., pp. 309 y ss.

29 SSTS de 16 de enero de 2004 (RJ/428), 19 de enero de 2004 (RJ/558) y 6 de febrero de 2004 (RJ/972).

30 Cfr. STSJ de Canarias de 12 de marzo de 1998 (RJCA/821).

Por lo demás, la STSJ de Galicia de 19 de febrero de 2003 (JUR/266842) afirma lo siguiente: «no resulta obligado en virtud de lo establecido en el artículo 32 de la Ley de 9 de 12 de junio de 1987, antes citados, que cada vez que se aprueba la plantilla y la relación de puestos de trabajo se haya de entrar en la negociación a que tal precepto se refiere, pues sin negar la influencia que esa aprobación puede
} 
Las partes podrán acordar, entre otros, los siguientes aspectos ${ }^{31}: \operatorname{los}$ criterios de adscripción de los puestos de trabajo a los funcionarios, eventuales o laborales; la fijación o catalogación de los puestos de trabajo; la determinación de los requisitos exigidos para su desempeño; los sistemas de provisión de los mismos; la determinación del nivel del complemento de destino que corresponda a cada puesto de trabajo ${ }^{32}$; y los criterios de valoración objetiva para determinar los puestos de trabajo a los que se asigna el complemento específico ${ }^{33}$. Y todo ello con sujeción a las normas que dicte el Estado en desarrollo del mandato que le formula el artículo 90.2 de la LBRL y, en su defecto, a las que se contienen en el artículo 15 de la LMRFP y en el artículo 3.1 y en la Disposición Transitoria $2^{\mathrm{a}}$ del RD 861/1986, de 25 de abril, sobre régimen de retribuciones de los Funcionarios de la Administración Local ${ }^{34}$. Ciertamente, esta negociación se desarrollará en cumplimiento de una normativa impuesta en su práctica totalidad desde fuera. Pero ese espacio negocial, aun configurado como actividad preparatoria de la correspondiente disposición reglamentaria o resolución administrativa, no es susceptible de ser negado.

\section{b) Los Planes de Empleo}

El artículo 32.c) de la LORAP incluye, entre las materias negociables, «la preparación y diseño de los planes de oferta de empleo público», pero no los planes de empleo. Por ello, y como quiera que éstos no pueden confundirse con la oferta de empleo público, no cabe sino concluir que los mismos no se incluyen en el contenido de la negociación colectiva delimitado por la LORAP ${ }^{35}$. Sin embargo, debe tenerse en cuenta que con posterioridad el legislador ha dispuesto en la Disposición Adicional $7^{\mathrm{a}}$ de la Ley

\footnotetext{
representar in genere sobre las condiciones de trabajo $\{\ldots\}$ no siempre en el caso concreto puede tal aprobación repercutir en ello por ejemplo, si se reproduce lo que ya venía establecido o si, como dice el Concello que fue el supuesto de autos, la Corporación se limitó, sobre las remuneraciones que ya venían rigiendo, a aprobar las subidas establecidas al efecto en los artículos 22 y 23 de la ley estatal 54 de 27 de diciembre de 1999 sobre aprobación del presupuesto para el ejercicio del año 2000; y es que si no hay variaciones o estas son las establecidas con carácter obligatorio, falta tema de negociación».

${ }^{31}$ Cfr. STSJ de Canarias de 24 de abril de 2002 (JUR/250248).

32 STS de 3 de mayo de 2000 (RJ/4573) y STSJ de Castilla y León de 10 de septiembre de 1999 (RJCA/2502).

${ }^{33}$ STS de 3 de mayo de 2000 (RJ/4573) y STSJ de la Comunidad Valenciana de 18 de marzo de 2003 (JUR/22730).

${ }^{34}$ Cfr. RD 158/1996, de 2 de febrero, por el que se modifica el RD 861/1986.

35 STSJ de Canarias de 11 de febrero de 2002 (JUR/277385).
} 
22/1993, de 29 de diciembre, de Medidas fiscales, de reforma del régimen jurídico de la función pública y de la protección por desempleo, que los Planes de Empleo «serán objeto de negociación con las Organizaciones Sindicales más representativas, en los términos que establece la Ley 9/1987, de 12 de junio, de órganos de representación, determinación de las condiciones de trabajo y participación del personal al servicio de las Administraciones Públicas, sin perjuicio de lo previsto en el artículo 34 de la misma» ${ }^{36}$. Lo cual significa que, con independencia de que la aprobación de los Planes de Empleo corresponda al Pleno de la Corporación Local [art. 4.1.a) LBRL] ${ }^{37}$, las mesas de negociación podrán acordar los criterios a que se deben ajustar los distintos Planes de Empleo y las repercusiones que en materia de personal puedan tener las medidas contempladas en los mismos ${ }^{38}$.

\section{c) La preparación y diseño de los planes de oferta de empleo público}

De acuerdo con el artículo 32.c) de la LORAP, será objeto de negociación «la preparación y diseño de los planes de oferta de empleo público». De este modo, se obliga a las EE.LL. a negociar la preparación y diseño de los planes de oferta de empleo público ${ }^{39}$, ajustándose a la legislación básica del Estado sobre función pública (arts. 91.1 LBRL y 128.1 TRRL) y «a los criterios que reglamentariamente se establezcan en desarrollo de la normativa básica estatal para su debida coordinación con las ofertas de empleo del resto de las Administraciones Públicas» (art. 128.1 TRRL) ${ }^{40}$. De este modo, a la autonomía colectiva le corresponde diseñar el plan de oferta de empleo público, negociando los aspectos que repercutan sobre las condiciones de trabajo de los funcionarios públicos (la distribución de la oferta de empleo entre los distintos grupos, cuerpos, la promoción interna, los cri-

\footnotetext{
${ }^{36}$ En este mismo sentido se expresan el artículo 2.3 y la Disposición Adicional $7^{\text {a }}$ del RD 364/1995, de 10 de marzo, por el que se aprueba el Reglamento General de Ingreso del Personal al servicio de la Administración General del Estado y de Provisión de Puestos de Trabajo y Promoción Profesional de los Funcionarios Civiles de la Administración General del Estado.

37 A. Serrano Pascual, El personal de las Entidades Locales..., cit., p. 85.

${ }^{38}$ R. Roqueta Buj, La negociación colectiva en la función pública, cit., p. 270; y A. SERRANo PaSCUAL, El personal de las Entidades Locales..., cit., p. 84.

Por todos, R. RoQueta Buj, La negociación colectiva en la función pública, cit., pp. 270 y ss.

39 SSTS de 14 de abril de 2000 (RJ/4823) y 17 de febrero de 2003 (RJ/2112); y SSTSJ de Canarias de 2 de noviembre de 1995 (RJCA/1178), 29 de enero de 2001 (JUR/233117) y 24 de abril de 2002 (JUR/250248). Cfr. STS de 29 de mayo de 1997 (RJ/4534).

${ }^{40}$ Cfr. Disposición Adicional $19^{\mathrm{a}}$ de la LMRFP.
} 
terios de selección, la reserva en favor de minusválidos o las que se estimen conveniente,... etc.). En todo caso, con la redacción dada al artículo 32.c) de la LORAP, ha querido dejarse bien claro que la oferta de empleo público, en cuanto tal, no ha pasado a la esfera negocial, sino que continúa siendo objeto de decisión unilateral de la Administración ${ }^{41}$. Es decir, no se exige que anualmente se presente a la Mesa de negociación un proyecto cerrado de oferta de empleo público, sino que serán objeto de negociación la preparación y diseño de los planes de oferta de empleo público ${ }^{42}$. Lo que es objeto de negociación son los planes y actos preparatorios de dicha oferta.

\section{d) Los sistemas de ingreso, provisión y promoción profesional de los funcionarios públicos}

El artículo 32.g) de la LORAP incluye en la esfera de lo negociable «los sistemas de ingreso, provisión y promoción profesional de los funcionarios públicos». Referencias que hay que relacionar con los regímenes previstos en el Capítulo IV de la LMRFP ${ }^{43}$. Por lo demás, cuando se habla de sistemas de provisión se alude al concurso y a la libre designación, pudiendo entenderse comprendidas asimismo la redistribución y reasignación de efectivos, así como la adscripción provisional, las comisiones de servicios y la atribución temporal de funciones, tal como se desprende de los artículos 36 y siguientes del RD 364/1995, de 10 de marzo, por el que se aprueba el Reglamento General de Ingreso del Personal al Servicio de la Administración General del Estado y de Provisión de Puestos de Trabajo y Promoción Profesional de los funcionarios civiles de la Administración General del Estado, de modo que a dichos sistemas se refiere también el artículo 32.g) de la LORAP ${ }^{44}$. Pues bien, por lo que se refiere a los funcionarios de la Administración Local sin habilitación de carácter nacional, tales materias se encuentran reguladas por la normativa estatal y, en su caso, autonómica ${ }^{45}$,

\footnotetext{
41 Igual conclusión mantiene S. Del Rey GuANTER, Comentarios..., cit., p. 207, si bien se refiere al sistema normativo anterior.

42 Cfr. STSJ de Castilla-La Mancha de 18 de junio de 2001 (JUR/260174).

43 STS de 5 de mayo de 1998 (RJ/4723).

44 STSJ de Galicia de 10 de julio de 200 (JUR/5952, 2003).

45 En materia de selección, ha de estarse a lo dispuesto en los artículos 19.1 de la LMRFP, 91.2 y 100 de la LBRL, y 133 y 134 del TRRL. Asimismo, el apartado 2 de este último precepto dispone que serán aplicables en esta materia las normas del TRRL y las que dicte el Estado en uso de las autorizaciones contenidas en los artículos 98.1 y 100.2 de la LBRL, y en lo no previsto en ellas, la reglamentación que para el ingreso en la función pública establezca la respectiva Comunidad Autónoma, y supletoriamente el RD 364/1995. La provisión de puestos de trabajo se rige por lo dispuesto en los artículos 101 de la LBRL, 168 del TRRL y 20 de la LMRFP y en las normas que, en desa-
} 
estando sustraídas, por tanto, a la negociación colectiva de las EELL ${ }^{46}$. Por lo demás, la negociación colectiva tiene por objeto la normativa que ha de regular estos procedimientos, no cada supuesto concreto de selección, provisión de vacantes o reordenación de efectivos ${ }^{47}$. Tales decisiones quedan «extra-muros» de la negociación colectiva, por mor de lo dispuesto en el artículo 34.1 de la LORAP. Por consiguiente, no constituye materia negociable el contenido de las bases de los procesos selectivos ${ }^{48}$, de las convocatorias de pruebas para el nombramiento de funcionarios interinos ${ }^{49}$, de las convocatorias de provisión de puestos de trabajo por el sistema de libre designación ${ }^{50}$ o de redistribución de efectivos ${ }^{51}$. Por lo demás, la convocatoria y resolución de los procesos de selección y provisión de puestos de trabajo corresponde al Presidente de la Corporación (art. 102 LBRL): atribución que no se puede desconocer ni compartir con los representantes de los funcionarios ${ }^{52}$.

\subsection{Materias de índole retributiva}

De acuerdo con el artículo 32 de la LORAP, en materia retributiva serán objeto de negociación las siguientes cuestiones: «a) El incremento de

rrollo de la legislación básica en materia de función pública local, dicte la Administración del Estado, esto es, el RD 364/1995 y demás disposiciones de aplicación. Y la promoción interna de los funcionarios locales viene establecida en la normativa estatal básica (art. 22.1 LMRFP, arts. 134.2 y 169.2 TRRL y RD 896/1991, de 7 de junio, por el que se establecen las reglas básicas y los programas mínimos a que debe ajustarse el Procedimiento de Selección de los Funcionarios de la Administración Local) y en el desarrollo normativo de la legislación estatal básica efectuado por la correspondiente Comunidad Autónoma.

${ }^{46}$ Cfr. STS de 10 de febrero de 1997 (RJ/1409); y SSTSJ de Cataluña, de 23 de octubre de 2000 (RJCA/233, 2001), 23 de noviembre de 2000 (JUR/87226, 2001), 7 de noviembre de 2001 (RJCA/410, 2002) y 7 de diciembre de 2001 (RJCA/309, 2002); del País Vasco, de 6 de abril de 2001 (RJCA/1487); de Asturias, de 10 de mayo de 2002 (RJCA/594); de Andalucía, de 5 de noviembre de 2002 (JUR/42353, 2003); y de Extremadura, de 18 de marzo de 2003 (JUR/123676).

${ }^{47}$ STSJ de Castilla y León de 8 de marzo de 2002 (JUR/89762).

Cfr. Disposición Adicional $7^{\mathrm{a}}$ del RD 364/1995, de 10 de marzo.

48 STSJ de Cantabria de 18 de enero de 2000 (RJCA/13) y STSJ de Castilla y León de 8 de marzo de 2002 (JUR/89762).

49 En sentido contrario, las SSTSJ de la Comunidad Valenciana, de 16 de marzo de 2001 (JUR/183071); y de Castilla-La Mancha, de 2 de mayo de 2002 (JUR/197767) y 5 de junio de 2002 (RJCA/814).

${ }^{50}$ SSTSJ de Madrid de 22 de enero de 2000 (JUR/182442) y 16 de febrero de 2000 (JUR/280265).

${ }^{51}$ Cfr. SSTSJ de Baleares de 19 de marzo de 1999 (RJCA/571) y 10 de junio de 2003 (JUR/247257).

52 STSJ de Asturias de 10 de mayo de 2002 (RJCA/594) y STSJ de Aragón de 5 de noviembre de 2003 (JUR/88498, 2004). En sentido contrario, la STSJ de la Comunidad Valenciana de 12 de enero de $2000(\mathrm{RJCA} / 2352)$. 
retribuciones de los funcionarios y del personal estatutario de las Administraciones Públicas que proceda incluir en el Proyecto de Presupuestos Generales del Estado de cada año, así como el incremento de las demás retribuciones a establecer, para su respectivo personal, en los proyectos normativos correspondientes de ámbito autonómico y local. b) La determinación y aplicación de las retribuciones de los funcionarios públicos $\{\ldots\}$ j) Todas aquellas materias que afecten, de algún modo, $\{\ldots\}$ (a las) retribuciones $\{\ldots\}$ de los funcionarios públicos y cuya regulación exija norma con rango de Ley. k) Las materias de índole económica...».

En materia retributiva, sin embargo, el ámbito competencial de la autonomía colectiva local es muy limitado ${ }^{53}$. En efecto, la estructura de las retribuciones de los funcionarios públicos locales debe ser la misma que la dispuesta en la LMRFP para los funcionarios de la Administración del Estado (arts. 23 LMRFP y 93.1 y 2 LBRL), de forma que las mesas negociadoras locales no pueden crear conceptos retributivos no contemplados en la LMRFP ni alterar los rasgos que presentan los previstos en esta Ley ${ }^{54}$. Tampoco pueden concluir acuerdos negociales que impliquen un incremento de la masa retributiva global superior al autorizado para cada ejercicio económico por la correspondiente Ley de Presupuestos Generales del Estado, tal y como prescriben los artículos 93.3 de la LBRL, 154.1 del TRRL y 19. Uno de la Ley 61/2003, de 30 de diciembre, de Presupuestos Generales del Estado para 20045. Las

\footnotetext{
${ }^{53}$ Para una mayor información sobre este tema ver, por todos, R. RoQUETA BuJ, La negociación colectiva en la función pública..., cit., pp. 277 y ss., «El contenido de la negociación colectiva...», cit., pp. 316 y ss., y «La negociación colectiva de los funcionarios locales», cit., pp. 2505 y ss.; y P.A. MARTín PÉreZ, «La negociación colectiva...», cit., pp. 1067 y ss.

${ }^{54}$ En este sentido, las SSTS de 30 de mayo de 1992 (RJ/4454) y 22 de febrero de 1997 (RJ/1497). Idea en la que insisten las SSTSJ de Asturias, de 18 de mayo de 1998 (RJCA/1758) y 19 de abril de 1999 (RJCA/961); de Galicia, de 15 de abril de 1998 (RJCA/1708); de Asturias, de 19 de abril de 1999 (RJCA/961); de Andalucía, de 9 de junio de 1999 (RJCA/1466) y 4 de enero de 2000 (RJCA/1); de Asturias, de 27 de abril de 2001 (JUR/167384) y 10 de mayo de 2002 (RJCA/594); de Castilla y León, de 5 de diciembre de 2001 (JUR/24166); de Cantabria, de 29 de julio de 2002 (RJCA/748); de Andalucía, de 5 de noviembre de 2002 (JUR/42353, 2003) y 19 de noviembre de 2002 (JUR/144738, 2003); y de Extremadura, de 18 de marzo de 2003 (JUR/123676).
}

Por lo demás, la asignación a los funcionarios que realicen funciones de categoría superior como complemento de productividad de una cantidad equivalente a la diferencia de categoría o la deducción en las retribuciones complementarias, del incremento de la retribución básica por cambio de grupo, son materias «indisponibles» en cuanto no incardinadas en el ámbito de las competencias de las Corporaciones Locales. En este sentido se expresan, por ejemplo, las SSTSJ de Asturias, de 18 de mayo de 1998 (RJCA/1758); de la Comunidad Valenciana, de 30 de abril de 2002 (JUR/179667, 2003); de Extremadura, de 18 de marzo de 2003 (JUR/123676); y de la Comunidad Valenciana, de 23 de junio de 2003 (JUR/24123, 2004).

${ }^{55}$ En este sentido, la jurisprudencia anula los Acuerdos locales que suponen un incremento retributivo superior al permitido por las sucesivas Leyes de Presupuestos Generales del Estado. Así, entre 


\section{cuantías de las retribuciones básicas de los funcionarios locales y de los com- plementos de destino asignados a sus puestos de trabajo deben coincidir con las que para cada ejercicio económico establezca la correspondiente Ley de Presupuestos Generales del Estado, tal y como se desprende de lo dispuesto en los artículos 24 de la LMRFP, 93.1 de la LBRL y 3.4 del RD 861/1986, de}

otras, las SSTS de 23 de julio de 1996 (RJ/5743), 30 de junio de 1997 (RJ/6138), 25 de septiembre de 2003 (RJ/7198) y 2 de marzo de 2004 (RJ/2406); y las SSTSJ del País Vasco, de 13 de mayo de 1992 (AA. a)37/1993) y 29 de noviembre de 1996 (AA. a)89/1997); de Asturias, de 19 de abril de 1999 (RJCA/961); de Castilla-La Mancha, de 15 de septiembre de 1999 (RJCA/3197); de la Comunidad Valenciana, de 17 de febrero de 1999 (RJCA/490); de Asturias, de 19 de abril de 1999 (RJCA/961); de Cantabria, de 27 de febrero de 2002 (RJCA/515); de Asturias, de 10 de mayo de 2002 (RJCA/594); de Cantabria, de 29 de julio de 2002 (RJCA/748); de Andalucía, de 5 de noviembre de 2002 (JUR/42353, 2003); de Madrid, de 19 de noviembre de 2002 (JUR/144738, 2003); de Cataluña, de 28 de febrero de 2003 (JUR/222208); y de Cantabria, de 6 de junio de 2003 (RJCA/809). En cuanto a las excepciones a la aplicación de los topes establecidos en las leyes presupuestarias, véase la STSJ de Andalucía de 12 de marzo de 2002 (AS/3657).

Cfr. C. Alfonso Mellado, «La negociación colectiva de los funcionarios públicos», RDS, n. ${ }^{\circ} 13$, 2001, pp. 9 y ss.; F. Alonso CARBAJO, «Comentario a la Sentencia de la Audiencia Nacional de 7 de noviembre de 2000», A.A., n. ${ }^{\circ} 15,2001$, pp. 577 y ss.; F. De BorJa LóPEZ-JuRAdo Escribano, «El control judicial sobre el incremento de las retribuciones de los funcionarios», $A S$, n. $^{\circ} 20,2001$, pp. 25 y ss.; A. Gallego Anabitarte, «La Sentencia de la Audiencia Nacional de 7 de noviembre de 2000 sobre retribución de funcionarios: entre el comentario político y el análisis jurídico», Actualidad Jurídica Aranzadi, n. ${ }^{\circ}$ 473, 2001, pp. 1 y ss.; P. Gómez CABALlero, P., «La vinculación de los acuerdos colectivos en el ámbito de la función pública (A propósito de la sentencia de la Audiencia Nacional de 7 de noviembre de 2000)», $R L$, n. ${ }^{\circ} 13$, 2001, pp. 39 y ss.; L. MARTín CONTRERAS, «Aspectos procesales de una polémica (Comentarios a la sentencia de la Audiencia Nacional sobre la revisión salarial de los funcionarios)», Actualidad Jurídica Aranzadi, n. ${ }^{\circ} 475,2001$, pp. 1 y ss.; I. MARÍN ALONSO, «La congelación salarial de los funcionarios públicos mediante determinación unilateral del correspondiente ministro para las Administraciones Públicas. A propósito de la SAN de 7 de noviembre 2000 », $A S$, n. $^{\circ} 20,2001$, pp. 51 y ss.; R. MARTÍN JIMÉNEZ, «Retribuciones de los funcionarios públicos, acuerdos políticos y leyes de presupuestos», $A S$, n. $^{\circ} 20,2001$, pp. 43 y ss.; V.A. MARTíNEZ ABASCAL, «La eficacia de la negociación colectiva de los funcionarios: a propósito de la sentencia de la Audiencia Nacional de 7 de noviembre de 2000», $R L$, n. ${ }^{\circ} 13,2001$, pp. 17 y ss.; J.L. MARTínez LóPEZ, «Imperio de la Ley, retribuciones funcionariales y prudentia iuris de nuestros jueces» (I y II), Diario La Ley, n. ${ }^{\text {os }} 5258$ y 5259, 2001; P. MenÉNDEZ SEBAstián, «La sentencia de la Audiencia Nacional sobre el incremento retributivo de los funcionarios: crónica de un conflicto anunciado», A.S., n. ${ }^{\circ}$ 2, 2001, pp. 51 y ss.; $\mathrm{M}^{\mathrm{a}}$.J. RodríGUEz RAmOS, $\mathrm{M}^{\mathrm{a} . J .}$, «Erase una vez [...] la negociación colectiva de los funcionarios públicos», $A S$, n. ${ }^{\circ} 20,2001$, pp. 31 y ss.; R. ROQUETA BUJ, «La negociación del incremento de las retribuciones de los funcionarios públicos (a propósito de la Sentencia de la Audiencia Nacional de 7 de noviembre de 2000», $J L$, n. $^{\circ} 6,2001$, pp. 39 y ss.; A. Palomar OlmedA, «Apunte sobre la negociación colectiva de los funcionarios públicos tras las Sentencias del Tribunal Supremo de 21 de marzo de 2002», Actualidad Jurídica Aranzadi, n. ${ }^{\circ}$ 527, 2002, pp. 1 y ss.; J. GORELLI HERÁNDEZ, «Negociación colectiva y retribución de los funcionarios públicos (a propósito de la STS 21 marzo 2002 [RJ 2002, 4319]», $A S$, V/2002, pp. 1006 y ss.; y R. RoQueta BuJ, «Las Sentencias del Tribunal Supremo de 21 de marzo de 2002 sobre la negociación del incremento de las retribuciones de los funcionarios públicos», Temas Laborales, n. ${ }^{\circ} 13,2003$, pp. 13 y ss., y «Límites en los incrementos de las retribuciones en el sector público: Ley estatal de Presupuestos, Leyes autonómicas y acuerdos colectivos», en AA.VV., Derecho Vivo del Trabajo y Constitución, Estudios en Homenaje al Profesor Doctor Fernando Suárez González, Dirigido por Efrén Borrajo Dacruz, Madrid, 2004, pp. 111 y ss. 
25 de abril, sobre régimen de retribuciones de los Funcionarios de la Administración Local -redactado conforme al RD 158/1996-, por lo que estos extremos también quedan fuera del arbitrio de las mesas negociadoras loca$\operatorname{les}^{56}$.

A las Mesas de negociación que se constituyan en las EELL les corresponde, dentro del tope máximo global al incremento de la masa retributiva establecido en la Ley de Presupuestos Generales del Estado, determinar la cuantía global destinada a atender los complementos específicos, los complementos de productividad y las gratificaciones por servicios extraordinarios y proceder a su distribución individualizada. No obstante, la autonomía colectiva local se haya limitada por lo dispuesto en el artículo 7 del RD 861/1986, donde se dispone que «los créditos destinados a complemento específico, complemento de productividad, gratificaciones y, en su caso, complementos personales transitorios, serán los que resulten de restar a la masa retributiva global presupuestada para cada ejercicio económico, excluida la referida al personal laboral, la suma de las cantidades que al personal funcionario le correspondan por los conceptos de retribuciones básicas, ayuda familiar y complemento de destino» y que «la cantidad que resulte, con arreglo a lo dispuesto en el número anterior, se destinará: a) Hasta un máximo del 75 por 100 para complemento específico, en cualquiera de sus modalidades, incluyendo el de penosidad o peligrosidad para la Policía Municipal y Servicio de Extinción de Incendios. b) Hasta un máximo del 30 por 100 para complemento de productividad. c) Hasta un máximo del 10 por 100 para gratificaciones». Así pues, a los miembros de la Mesa general que se constituya en el seno de cada Entidad Local, después de determinar la cantidad global destinada a complemento específico, complemento de productividad, gratificaciones y, en su caso, complementos personales transitorios ${ }^{57}$, les corresponde negociar

\footnotetext{
56 SSTSJ de Asturias, de 18 de mayo de 1998 (RJCA/1758) y 19 de abril de 1999 (RJCA/961); de Castilla-La Mancha, de 15 de septiembre de 1999 (RJCA/3197); de Asturias, de 27 de abril de 2001 (JUR/167384); de Cantabria, de 29 de julio de 2002 (RJCA/748); y de Madrid, de 19 de noviembre de 2002 (JUR/144738, 2003).

57 A tal efecto, hay que comenzar fijando la masa retributiva global (que está en función de la del año anterior incrementada en el porcentaje de aumento consignado en la Ley de Presupuestos Generales del Estado) y restar la parte correspondiente a personal laboral y las retribuciones básicas, ayuda familiar y complementos de destino de los funcionarios (A. SERRAno Pascual, El personal de las Entidades Locales..., cit., p. 273). Debe subrayarse que, de conformidad con lo dispuesto en la Disposición adicional $9^{\text {a }}$ de la Ley 31/1991, de 30 de diciembre, de Presupuestos para 1992, queda suprimida la ayuda familiar y no se admite otra minusvalía que la regulada en la Ley 26/1990, de 20 de diciembre, por la que se establecen en la Seguridad Social prestaciones no contributivas -luego recogida en el Real Decreto Legislativo 1/1994, de 20 de junio, por el que se aprueba el Texto Refundido de la Ley General de la Seguridad Social-. Ver Ordeig Fos, El Sistema Español de Seguridad Social (Y de la Comunidad Europea), Madrid, 1993, p. 558.
} 
EL CONTENIDO DE LA NEGOCIACIÓN COLECTIVA DE LOS FUNCIONARIOS PÚBLICOS...

su distribución entre estos tres conceptos retributivos sin rebasar para cada uno de ellos los porcentajes señalados en el artículo 7 del RD $861 / 1986$ y, por supuesto, sin que la suma de los tres supere el $100 \%{ }^{58}$. Dentro del límite global destinado a complementos específicos, la cuantía a asignar a cada puesto de trabajo estará en función de la catalogación que del mismo efectúe la Entidad Local atendiendo a los criterios de valoración objetiva para la catalogación de puestos de trabajo acordados en la Mesa general de negociación ${ }^{59}$. A las mesas negociadoras les corresponde también distribuir la cuantía global destinada al complemento de productividad entre los diferentes programas o áreas y fijar los criterios técnicos de valoración de los factores a tener en cuenta en su distribución individualizada entre los diferentes funcionarios ${ }^{60}$, así como determinar los criterios a seguir en la asignación individual de las gratificaciones por servicios extraordinarios ${ }^{61}$.

Por último, las indemnizaciones por razón del servicio o por residencia de los funcionarios públicos locales serán las mismas que correspondan al personal al servicio de la Administración del Estado (art. 157 TRRL), por lo que estas materias escapan al ámbito de la autonomía colectiva local ${ }^{62}$.

\title{
4.3. Materias de índole funcionarial
}

El artículo 32 de la LORAP incluye en el contenido de la negociación colectiva las materias de índole funcionarial. Así, de acuerdo con el

\footnotetext{
58 STSJ de Cantabria de 27 de febrero de 2002 (RJCA/515).

59 STS de 3 de junio de 2000 (RJ/4573); SSTSJ de Castilla-La Mancha, de 3 de marzo de 2001 (JUR/169797); de la Comunidad Valenciana, de 18 de marzo de 2003 (JUR/22730); y de Cataluña, de 4 de mayo de 2004 (JUR/194311).
}

\begin{abstract}
Ahora bien, la catalogación de los puestos de trabajo deberá tomar en consideración las condiciones particulares que se contemplan en el artículo 23.3.b) de la LMRFP [STSJ de la Comunidad Valenciana (AA.@25/1998) y STSJ de Castilla-La Mancha de 15 de septiembre de 1999 (RJCA/3197)].

60 STSJ de Cantabria de 27 de febrero de 2002 (RJCA/515).

61 STSJ de Castilla-La Mancha de 2 de abril de 2002 (RJCA/665). En cuanto al alcance de la autonomía colectiva local en materia de gratificaciones por servicios extraordinarios, véanse las SSTS de 27 de julio de 1994 (RJ/6600) y 14 de octubre de 1996 (AL 179/1997); y las SSTSJ de Andalucía, de 9 de junio de 1999 (RJCA/1466) y 4 de enero de 2000 (RJCA/1); de Madrid, de 21 de septiembre de 1999 (RJCA/4508), 15 de julio de 2000 (JUR/57494, 2001) y 24 de enero de 2001 (JUR/184198); y de Castilla-La Mancha, de 3 de marzo de 2001 (JUR/169797).

62 Así lo señalan las SSTS de 30 de junio de 1997 (RJ/6138) y 2 de marzo de 2004 (RJ/2406); y las SSTSJ de Andalucía, de 9 de junio de 1999 (RJCA/1466); de Asturias, de 10 de mayo de 2002 (RJCA/594); y de Extremadura, de 18 de marzo de 2003 (JUR/123676).
\end{abstract}


mismo, son susceptibles de negociación: «e) La determinación de los programas y fondos para la acción de promoción interna, formación y perfeccionamiento $\{\ldots\}$ j) Todas aquellas materias que afecten, de algún modo, al acceso a la Función Pública, Carrera administrativa $\{\ldots\}$ o a las condiciones de trabajo de los funcionarios públicos y cuya regulación exija norma con rango de Ley. k) Las materias $\{\ldots\}$ de prestación de servicios $\{\ldots\}$ y en general cuantas otras afecten a las condiciones de trabajo...».

El campo de maniobra de la negociación colectiva local en cuanto a la regulación de la prestación de trabajo de los funcionarios públicos desde su perspectiva temporal es también muy limitado. En efecto, la jornada de trabajo de los funcionarios públicos locales «será en cómputo anual la misma que se fije para los funcionarios de la Administración Civil del Estado» y «se les aplicarán las mismas normas sobre equivalencia y reducción de jornada» (art. 94 LBRL). Por consiguiente, la jornada anual equivalente a 1747 horas que se fija para el personal civil al servicio de la Administración General del Estado por la Resolución de 10 de marzo de 2003, de la Secretaría de Estado para la Administración Pública (BOE 133-2003), no podrá ser elevada ni rebajada por las mesas negociadoras locales $^{63}$. A éstas les corresponderá repartir la jornada anual a lo largo del

${ }^{63}$ Por todas, las SSTS de 7 de abril, 13 de julio y 7 de noviembre de 1995 (RJ/3208, 5746 y 8173), 5 de diciembre de 1997 (RJ/307, 1998) y 2 de marzo de 2004 (RJ/2406); y las SSTSJ de Asturias, de 18 de mayo de 1998 (RJCA/1758) y 19 de abril de 1999 (RJCA/961); de la Comunidad Valenciana, de 2 de noviembre de 2000 (JUR/163960, 2001); de Andalucía, de 7 de febrero de 2001 (JUR/298183); del País Vasco, de 6 de abril de 2001 (RJCA/1487); de Asturias, de 27 de abril de 2001 (JUR/167384); y de Cantabria, de 11 de octubre de 2001 (RJCA/1511), 8 de abril de 2002 (RJCA/773) y 29 de julio de 2002 (RJCA/748).

\begin{abstract}
Ahora bien, el hecho de que la jornada de los funcionarios de la Administración Civil del Estado estuviese fijada en cómputo semanal según la Instrucción de 21 de diciembre de 1983, y que la igualdad establecida en el artículo 94 de la LBRL lo sea en cómputo anual, exigía, a juicio del Tribunal Supremo, que quien impugnase por ilegal la jornada anual de unos determinados funcionarios públicos locales, estableciera cuál era en cómputo anual la jornada de los funcionarios de la Administración del Estado, pues es este parámetro temporal de referencia, y no el semanal, el que cuenta [SSTS de 13 de julio y 28 de noviembre de 1995 (RJ/5746 y 8823), 19 de febrero de 1996 (RJ/1582 y 1583), 5 de diciembre de 1997 (RJ/9327) y 27 de septiembre de 2000 (RJ/8597). Cfr. STSJ de Asturias de 10 de mayo de 2002 (RJCA/594)]. Por esta razón, no es de recibo el criterio seguido por algunas resoluciones judiciales que declaran la ilegalidad de determinados acuerdos locales sobre la base de que la jornada semanal por ellos establecida supera la jornada semanal prevista para los funcionarios de la Administración Civil del Estado por la Instrucción de 21 de diciembre de 1983 y la Resolución de 27 de abril de 1995, de la Secretaría de Estado para la Administración Pública. Así proceden, entre otras, las SSTSJ de Galicia, de 15 de abril de 1998 (RJCA/1708); de Asturias, de 18 de mayo de 1998 (RJCA/1758) y 19 de abril de 1999 (RJCA/961); de Castilla-La Mancha, de 3 de marzo de 2001 (JUR/169797); de Cantabria, de 8 de abril de 2002 (RJCA/773); de Extremadura, de 18 de julio de 2002 (RJCA/848) y 27 de septiembre de 2002 (JUR/265210); de Madrid, de 19 de noviembre de 2002 (JUR/144738, 2003); y de Cataluña, de 28 de febrero de 2003 (JUR/222208).
\end{abstract}


EL CONTENIDO DE LA NEGOCIACIÓN COLECTIVA DE LOS FUNCIONARIOS PÚBLICOS...

año, pudiendo distribuirla desigualmente entre los días de la semana, entre los días y/o las semanas del año, o entre los meses del año, siempre que el total anual de horas de trabajo sea igual al fijado a nivel estatal ${ }^{64}$. De este modo, pueden establecer descansos diarios y/o semanales diferentes a los disfrutados por el personal civil al servicio de la Administración General del Estado ${ }^{65}$. No obstante, como quiera que, según el artículo 94 de la LBRL, a los funcionarios públicos locales se les deben aplicar «las mismas normas sobre equivalencia y reducción de jornada» que a los funcionarios de la Administración del Estado, no pueden incrementar el descanso diario de treinta minutos computables como tiempo de trabajo efectivo que fija el apartado primero de la Resolución de 10 de marzo de $2003^{66}$. También pueden pactar el descanso en días que legalmente no son festivos siempre que ello no signifique una disminución de la jornada anual ${ }^{67}$. En materia de horario de trabajo y calendario laboral no existe ninguna previsión legal, por lo que estos aspectos se podrán negociar en el ámbito local ${ }^{68}$.

Por último, debe tenerse en cuenta que «los funcionarios de la Administración Local tendrán derecho a las recompensas, permisos, licencias y vacaciones retribuidas previstas en la legislación sobre función pública de la Comunidad Autónoma respectiva y, supletoriamente, en la aplicable a los funcionarios de la Administración del Estado» (art. 142 TRRL). Lo cual significa que las EELL carecen de competencias para pactar el régimen jurídico aplicable en estas materias ${ }^{69}$. Es decir, no pueden introducir

\footnotetext{
64 STS de 15 de diciembre de 2003 (RJ/9011) y STSJ de Asturias de 10 de mayo de 2002 (RJCA/594).

65 Cfr. STSJ de Andalucía de 5 de noviembre de 2002 (JUR/42353, 2003).

66 En este sentido, la STSJ de la Comunidad Valenciana de 12 de enero de 2000 (RJCA/2352); la STSJ de Aragón de 28 de noviembre de 2001 (JUR/93207, 2001); y la STSJ de Andalucía, de 5 de noviembre de 2002 (JUR/42353, 2003). Cfr. la STSJ de Asturias de 10 de mayo de 2002 (RJCA/394).

${ }^{67}$ En sentido contrario, las SSTSJ de la Comunidad Valenciana, de 12 de enero de 2000 (RJCA/2352); de Asturias, de 10 de mayo de 2002 (RJCA/594); y de Cantabria, de 29 de julio de
} 2002 (RJCA/748).

68 Por todas, las SSTSJ de Baleares, de 19 de marzo de 1999 (RJCA/571); de la Comunidad Valenciana, de 17 de febrero de 1999 (RJCA/490) y 7 de julio de 2000 (JUR/83511); del País Vasco, de 22 de diciembre de 2000 (JUR/255549, 2001); de Asturias, de 27 de abril de 2001 (JUR/167384); y de Castilla y León, de 15 de noviembre de 2002 (JUR/15370, 2003).

69 Así lo señalan, entre otras, las SSTS de 16 de noviembre de 1994 (RJ/555, 1995), 16 de junio de 1995 (AL 16/1996), 30 de octubre de 1995 (RJ/7907), 4 de diciembre de 1995 (RJ/1564, 1996), 14 de octubre de 1996 (AL 179/1997), 10 de febrero y 30 de junio de 1997 (RJ/1409 y 6138), 21 de noviembre de 1997 (RJ/306, 1998) y 5 de diciembre de 1997 (RJ/307, 1998); y las SSTSJ de Canarias, de 21 de mayo de 1999 (RJCA/1424); de Andalucía, de 9 de junio de 1999 (RJCA/1466); de la Comunidad Valenciana, de 17 de febrero de 1999 (RJCA/490); de Andalucía, de 9 de junio de 1999 (RJCA/1466); de la Comunidad Valenciana, de 12 de enero de 2000 (RJCA/2352); de Canarias, de 7 
permisos o licencias nuevas ni ampliar las vacaciones o regularlas en términos distintos de los fijados por la Comunidad Autónoma, o en su defecto, por el Estado. Pese a lo cual «no se excluye la posibilidad de que los Órganos de las Corporaciones Locales que, en materias, como la de organización de sus servicios, sean de su competencia exclusiva, convengan con su personal lo relacionado con el ejercicio del derecho que éste tiene de disfrutar vacaciones, porque esto es cuestión distinta de que, al usar de tal facultad, se infrinja el régimen general que viniera establecido con riguroso carácter imperativo» [STS de 30 de mayo de 1992 (RJ/4454)]. De esta manera, a nivel local se puede pactar todo lo relacionado con las fechas y forma de disfrute de las vacaciones ${ }^{70}$.

En materia de situaciones administrativas, debe tenerse en cuenta lo dispuesto en el artículo 140.2 del TRRL, conforme al cual las situaciones de los funcionarios de la Administración Local «se regularán por la normativa básica estatal, y por la legislación de función pública de la respectiva Comunidad Autónoma y, supletoriamente, por la legislación de los funcionarios de la Administración del Estado, teniéndose en cuenta las peculiaridades del régimen local». En consecuencia, las EELL carecen de competencia para establecer por vía contractual una regulación distinta en esta materia ${ }^{71}$.

\subsection{Materias de índole sindical}

De acuerdo con lo dispuesto en las letras h) y k) del artículo 32 de la LORAP, entre las materias susceptibles de negociación, figuran «las propuestas sobre derechos sindicales y de participación» y las «materias de índole $\{\ldots\}$ sindical $\{\ldots\}$ y en general cuantas otras afecten $\{\ldots\}$ al ámbi-

de junio de 2000 (JUR/304893); de Aragón, de 28 de noviembre de 2000 (JUR/93207, 2001); de Castilla-La Mancha, de 30 de noviembre de 2000 (RJCA/2414); de Andalucía, de 7 de febrero de 2001 (JUR/298183); de Castilla-La Mancha, de 3 de marzo de 2001 (JUR/169797); de Asturias, de 10 de mayo de 2002 (RJCA/594); de Andalucía, de 5 de noviembre de 2002 (JUR/42353, 2003); de Madrid, de 19 de noviembre de 2002 (JUR/144738) y 26 de noviembre de 2002 (JUR/144862, 2003); y de Extremadura, de 18 de marzo de 2003 (JUR/123676).

${ }^{70}$ STSJ de la Comunidad Valenciana de 17 de febrero de 1999 (RJCA/490) y 11 de abril de 2000 (JUR/35176, 2001); y STSJ de Extremadura de 18 de marzo de 2003 (JUR/123676).

${ }^{71}$ SSTSJ de Asturias, de 19 de abril de 1999 (RJCA/961); de la Comunidad Valenciana, de 17 de febrero de 1999 (RJCA/490); de Cataluña, de 23 de octubre de 2000 (RJCA/233, 2001), 23 de noviembre de 2000 (JUR/87226, 2001), 7 de noviembre de 2001 (RJCA/410, 2002) y 7 de diciembre de 2001 (RJCA/309, 2002); de Andalucía, de 7 de febrero de 2001 (JUR/298183); de Cantabria, de 11 de octubre de 2001 (RJCA/1511); de Asturias, de 10 de mayo de 2002 (RJCA/594); y de Andalucía, de 5 de noviembre de 2002 (JUR/42353, 2003). 
to de relaciones de los funcionarios públicos y sus Organizaciones Sindicales con la Administración ${ }^{72}$. Centrando la atención en el espacio en el que puede desenvolverse la negociación colectiva propiamente dicha ${ }^{73}, \mathrm{y}$ por lo que se refiere al alcance que debe otorgarse a la expresión «materias de índole sindical», debe sostenerse un sentido amplio de actividad sindical, entendida como actuación colectiva de los funcionarios públicos y de sus representantes tanto unitarios (a) como sindicales (b) ${ }^{74}$.

a) La LORAP, al regular las representaciones unitarias ha dejado poco espacio real a la intervención de la autonomía colectiva. La minuciosidad de detalles del Capítulo II de esta disposición legal, abarcando tanto los aspectos generales como los puntuales, da lugar a que difícilmente pueda realizarse una labor innovadora por parte de las mesas de negociación ${ }^{75}$.

Pero, vayamos por partes.

$\left.1^{\circ}\right)$ El apartado 4 del artículo 7 de la LORAP dispone con carácter de norma básica que cada uno de los Ayuntamientos, Diputaciones Provinciales, Cabildos, Consejos Insulares y demás Entidades Locales constituyen una «unidad electoral» ${ }^{76}$. Por consiguiente, este precepto se impone como regulación unitaria de carácter general y de derecho necesario, sin que frente a ella pueda prevalecer un Acuerdo o Pacto local ${ }^{77}$.

\footnotetext{
72 No obstante, la STS de 10 de febrero de 1997 (RJ/1409) afirma lo siguiente: «Apartado 1.H) del fallo de la sentencia, que anula el Título Sexto del IX ARCEPAFE («Del régimen de ejercicio del derecho de sindicación, acción sindical, representación, participación, reunión y negociación colectiva de los empleados públicos forales»), nulidad pertinente porque la materia debe regirse imperativamente por la Ley 9/1987, careciendo los Ayuntamientos de capacidad negociadora para modificar la normativa legal sobre la materia».

${ }^{73}$ Cfr. R. Roqueta Buj, La negociación colectiva en la función pública, cit., pp. 253 y ss.

74 J. CRUZ Villalon, «Juntas y Delegados de Personal: conceptos, ámbitos de actuación y competencias», en AA.VV., Seminario sobre relaciones colectivas en la función pública, Sevilla, 1990, pp. 93 y ss.; J.J. Fernández Domínguez. y S. Rodríguez Escanciano, La Negociación Colectiva de los Funcionarios Públicos, Barcelona, 1996, p. 172; y STSJ del País Vasco de 6 de abril de 2001 (RJCA/1487).
}

Sobre este tema véase R. RoQuETA BUJ, «Los derechos y garantías sindicales en la negociación colectiva funcionarial», $A A$., n. ${ }^{\circ} 35,2002$, pp. 719 y ss.

75 S. Del Rey Guanter, Comentarios.., cit., p. 215.

${ }^{76}$ Cfr. Disposición final de la LORAP.

77 En este sentido, la STSJ de Cataluña de 23 de octubre de 2001 (RJCA/233, 2001) al resolver un recurso contencioso-administrativo deducido contra el Acuerdo de la Asamblea de la Mancomunidad de Municipios del Area Metropolitana de Barcelona de 19 de diciembre de 1996, por el que se creaba un único Comité Unitario de personal, representativo de todos los trabajadores, tanto funcionarios como laborales de todas las entidades que operan en el espacio metropolitano, afirma lo siguiente: «el Acuerdo de autos vulnera el conjunto de preceptos legales antes dichos en cuanto que aprueba 
$\left.2^{\circ}\right)$ El número de miembros de las Juntas de Personal y de Delegados de Personal a designar por los funcionarios públicos en cada circunscripción electoral viene determinado por los artículos 5 y 8 de la LORAP. Tales preceptos no tienen, al igual que sucede en el caso de los trabajadores, carácter de mínimos mejorables, sino de condiciones legales de derecho necesario absoluto y, a mayor abundamiento, de carácter básico ${ }^{78}$. Por consiguiente, el número de representantes unitarios no es ampliable a través de la negociación colectiva.

$\left.3^{\circ}\right)$ Las facultades de los representantes unitarios se encuentran enumeradas con carácter exhaustivo en el artículo 9 de la LORAP ${ }^{79}$. Por lo que, aunque nada impide que las disposiciones estatales de adecuado rango puedan modificar o ampliar tales facultades, no parece posible que ello se haga mediante Acuerdos o Pactos, pues el antecitado precepto carece de una cláusula, como la que contiene la Ley Orgánica 11/1985, de 2 de agosto, de Libertad Sindical (LOLS), respecto de los derechos de las secciones sindicales y delegados sindicales, en la que se reconozca tal posibilidad $^{80}$. Ahora bien, las mesas de negociación podrán abordar puntos no tratados por el legislador en relación con las facultades previstas en el artículo 9 de la LORAP (las formas de transmisión de la información que la Administración debe proporcionar a los representantes unitarios, las formas en que éstos deben emitir sus opiniones sobre las materias objeto de consulta, el carácter de la participación de los representantes unitarios en la gestión de las obras sociales para el personal establecidas en la Admi-

unos pactos que, al margen y con desconocimiento de la normativa estatal que regula el régimen estatutario de la función pública, establecen y crean en el ámbito de la negociación colectiva, unos órganos unitarios de negociación ajenos a los establecidos en la legislación estatal en el ámbito de los entes locales, y de ámbito supralocal, desconocidos en la legislación funcionarial aplicable, con directa vulneración de su contenido. Creación y regulación que se lleva a cabo sin habilitación ni competencia legal alguna de la entidad recurrente para su establecimiento y regulación; careciendo, asimismo, la Mancomunidad demandada de competencia para delegar, al margen de lo establecido en la Ley, la legitimación y las atribuciones negociadoras, que en su estricto ámbito competencial gozan los municipios que la integran, en favor de los órganos unitarios que se crean y refieren en dicho Acuerdo». Sentencia que ha sido confirmada por la STS de 9 de enero de 2001 (RJ/1630) sobre la base de que el «Area Metropolitana de Barcelona» carece de existencia.

78 Cfr. Disposición final de la LORAP.

Una excepción a la regla general se da en el caso de Navarra. Ver la STC 140/1990, de 20 de septiembre, y M $\mathrm{M}^{\mathrm{a}}$ CASAS BAAMONDE, «Representaciones unitarias de funcionarios públicos, competencias autonómicas y derechos históricos locales; algunas determinaciones básicas, y no básicas, de la Ley 9/1987, de 12 de junio», REDT, n. ${ }^{\circ} 48,1991$, pp. 641 y ss.

79 Ver J. Cruz Villalon, «Juntas...», cit., pp. 95 y 96; S. Del Rey Guanter, Comentarios.., cit., p. 83; y T. Sala Franco y R. Roqueta Buj, Los derechos.., cit., p. 135.

${ }^{80}$ STS de 5 de mayo de $1994(\mathrm{RJ} / 4315)$. 
nistración, concretar la participación y funciones en materia de prevención de riesgos laborales, etc., e incluso, ampliar las materias sobre las que versen las facultades de información activa o pasiva ${ }^{81}$. Pero la intervención de la autonomía colectiva no puede desvirtuar el sentido y la finalidad de cada una de las facultades legales ni el significado que las mismas tienen respecto a la función de tales representaciones en el esquema orgánico global contemplado por la LORAP.

$4^{\circ}$ ) En cuanto a la posibilidad de que el estatuto jurídico de los representantes unitarios, esto es, el conjunto de garantías y facilidades que el artículo 11 de la LORAP les reconoce, pueda ser modificado o mejorado por Acuerdos o Pactos, la respuesta parece ser de carácter negativo, ya que, en contraste con el artículo 10.3 de la LOLS, no hay ninguna indicación legal al respecto. Por consiguiente, el crédito horario que la letra d) del antecitado precepto concede a las representaciones unitarias de los funcionarios públicos no puede ser modificado o incrementado por la negociación colectiva ${ }^{82}$. Lo que sí parece posible, y en ciertos aspectos casi obligado, es que la negociación concrete o especifique las condiciones en que se pueden desarrollar las garantías y facilidades contempladas en la Ley.

b) En materia estrictamente sindical, los Acuerdos y Pactos pueden insertar cláusulas que traten de fortalecer la presencia sindical en los centros de trabajo como las referidas a las secciones y delegados sindicales ${ }^{83}$. Y ello no sólo porque, en virtud del artículo 32.k) de la LORAP, las materias de índole «sindical» sean susceptibles de negociación, sino también porque la propia LOLS en numerosas ocasiones atribuye a sus previsiones el carácter de normas mínimas mejorables por la autonomía colectiva: derechos de las secciones sindicales (art. 8.2); número de delegados sindicales (art. 10.2); competencias y derechos de los delegados sindicales (art. 10.3).

Pero, como en el caso anterior, vayamos por partes.

$\left.1^{\circ}\right)$ El artículo 8.2 de la LOLS reconoce a las secciones sindicales de los sindicatos más representativos y a las de aquellos que, sin serlo, cuenten

\footnotetext{
${ }^{81}$ STS de 15 de diciembre de 2003 (RJ/9011).

${ }^{82}$ En este sentido, se expresan P. Gómez Caballero, Los Derechos Colectivos..., cit., p. 235; y la STSJ de Cantabria de 11 de octubre de 2001 (RJCA/1511).

${ }^{83}$ En este sentido, la STSJ del País Vasco de 6 de abril de 2001 (RJCA/1487). La STSJ de Andalucía de 7 de febrero de 2001 (JUR/298183), sin embargo, sostiene que el ámbito relativo a la acción sindical o derechos sindicales queda vedado a la negociación colectiva a nivel local, habiendo de regirse por la LOLS. Sobre el papel de la negociación colectiva en este ámbito ver M. ÁLVAREZ DE LA Rosa, La organización del sindicato en los lugares del trabajo (Empresa y Administración Pública), Madrid, 1991, pp. 41 y ss.
} 
con representación en los órganos de representación unitaria de los funcionarios públicos una serie de derechos (derecho a un tablón, a la negociación colectiva y a un local). Tales derechos se establecen con carácter de mínimos, al señalarse expresamente que ello se hace «sin perjuicio de lo que se establezca mediante convenio colectivo». Expresión que hay que entender, bien como que los Acuerdos y Pactos pueden extender algunos de estos derechos en todo o en parte a cualesquiera secciones sindicales, bien que pueden establecer regulaciones específicas para los derechos aquí mencionados mejorando o eliminando algunos de los requisitos legales previstos para su disfrute, o bien que pueden establecer derechos adicionales $^{84}$. En ningún caso, los Acuerdos o Pactos pueden restringir los derechos que a estas secciones sindicales privilegiadas se reconocen en la LOLS $^{85}$.

$\left.2^{\circ}\right)$ El número de delegados sindicales establecido en la escala del artículo 10.2 de la LOLS es un mínimo de derecho necesario relativo mejorable por la negociación colectiva funcionarial ${ }^{86}$. Ahora bien, a la

84 T. Sala Franco y I. Albiol Montesinos, Derecho Sindical, Valencia, 2000, pp. 275-276; y T. Sala Franco y R. RoQueta Buj, Los derechos..., cit., p. 177.

Esta afirmación quiebra, sin embargo, en relación a la negociación colectiva, ya que no existe concesión alguna al libre juego de la autonomía colectiva para que modifique las reglas relativas a la legitimación negocial previstas en la LOLS y en la LORAP. Las partes negociadoras no pueden alterar las condiciones que deben cumplir los sujetos sindicales para negociar. Tal conclusión ha mantenido el Tribunal Constitucional en relación a las reglas previstas en el artículo 87.1 del ET. En este sentido, la STCO 73/1984, de 27 de junio, afirma que «las reglas relativas a la legitimación constituyen un presupuesto de la negociación colectiva que escapa al poder de disposición de las partes negociadoras, que no pueden modificarlas libremente, pues $\{\ldots\}$ en la negociación inciden derechos de carácter sindical que no pueden ser desconocidos» (en el mismo sentido la STCO 184/1991, de 30 de septiembre). Pero dejando al margen esta regulación que afecta al llamado «orden público laboral», el resto de derechos mencionados en el artículo 8.2 de la LOLS pueden verse mejorados o ampliados a través de la negociación colectiva. No obstante, debe tenerse en cuenta que la LORAP ha mejorado las previsiones de la LOLS, al extender los derechos a los tablones y locales a todas las secciones sindicales con independencia de la representatividad del sindicato de procedencia, si bien obligándoles a compartir los locales con las Juntas de Personal, y reconocer tales derechos en el ámbito del «centro de trabajo» (establecimiento) y no en el ámbito de la «unidad electoral», como resultaría de la aplicación estricta de la LOLS.

${ }^{85}$ La STS de 22 de octubre de 1993 ( $A L$ 12/1994), al enjuiciar el artículo 54.1 del Acuerdo concertado entre el Servicio Vasco de Salud y los Sindicatos ELA-STV y UGT, por el que se sustituye la entrega de locales a las secciones sindicales por una compensación económica a repartir entre los firmantes, señala que el «mismo contiene un tratamiento desigual entre sindicatos suficientemente representativos... (que) se revela como carente de justificación, no respondiendo a criterios objetivos y razonables, sino a un criterio subjetivo e injustificado que incluso puede suponer un acto de injerencia empresarial prohibido en el artículo 13, párrafo segundo, de la Ley Orgánica de Libertad Sindical».

${ }^{86}$ Así lo subrayan M. ÁlVAREZ DE LA Rosa, La organización del sindicato..., cit., p. 110; P. GóMEZ Caballero, Los Derechos Colectivos..., cit., p. 230; T. Sala Franco y R. Roqueta Buj, Los derechos..., cit., p. 181, y la sentencia del Juzgado de lo Social n. ${ }^{\circ} 6$ de Granada de 23 de mayo de 1991 
hora de delimitar el margen de maniobra de ésta, hay que atender a una interpretación sistemática de los apartados primero y segundo del artículo 10 de la LOLS. El apartado primero establece los requisitos necesarios para que las secciones sindicales puedan estar representadas por delegados sindicales (una plantilla mínima de 250 funcionarios y la presencia del sindicato en la Junta de Personal), sin mencionar la posibilidad de que la negociación colectiva pueda alterarlos. De este modo, parece que la autonomía colectiva no puede rebajar el número de funcionarios públicos necesarios para disponer de un delegado sindical ni eliminar la necesidad de contar con un representante en la Junta de Persona ${ }^{87}$. El apartado segundo del artículo 10 de la LOLS comienza señalando que «bien por acuerdo, bien a través de la negociación colectiva, se podrá ampliar el número de delegados establecidos en la escala a la que hace referencia este apartado, que atendiendo a la plantilla de la empresa o, en su caso, de los centros de trabajo corresponden a cada uno de éstos». Interpretado literalmente el precepto parece que lo único que puede hacer la autonomía colectiva es ampliar el número de delegados sindicales correspondiente a cada uno de los tramos de la esca$\mathrm{la}^{88}$. Sin embargo, a continuación el legislador señala que «a falta de acuerdos específicos al respecto, el número de delegados sindicales por cada sección sindical de los sindicatos que hayan obtenido el 10 por 100 de los votos en la elección al Comité de Empresa o al órgano de representación en las Administraciones Públicas se determinará según la siguiente escala», con lo cual parece que ésta presenta un carácter netamente dispositivo, de forma que la negociación colectiva puede no sólo ampliar el número de delegados sindicales correspondiente a cada unos de sus tramos, sino también rebajar el número de funcionarios que figuran en cada tramo de la escala o, incluso, modificar dichos tramos. Ahora bien, el número de un delegado sindical a representar a aquellas secciones sindicales de los sindicatos que no hayan obtenido el 10 por 100 de los votos en la elección al órgano de representación unitaria resulta inmodificable, por la sencilla razón de que estas secciones sin-

(AL 8/1992). Y así, la STC 188/1995, de 18 de diciembre, afirma que «parece claro que la negociación colectiva no podría privar de lo anterior [la posibilidad de estar representados por delegados sindicales] a sindicatos a los que la LOLS les reconoce inequívocamente el derecho a estar representados».

87 En este sentido, la STS de 10 de enero de 1996 (RJ/166) afirma que «lo que el art. 10.2 citado remite al acuerdo o a la negociación colectiva, y en cuyo defecto establece la norma contenida en él, es la posible ampliación del «número de delegados establecidos en la escala a que hace referencia este apartado», y no el límite mínimo de trabajadores precisos, según el art. 10.1, para que las secciones sindicales puedan estar representadas por Delegados Sindicales».

${ }^{88}$ En este sentido, P. Gómez Caballero, Los Derechos Colectivos..., cit., p. 230. 
dicales no entran en la escala, único supuesto de modificación admitido en el artículo 10.2 de la LOLS ${ }^{89}$.

Por lo demás, dada la eficacia jurídica normativa y eficacia personal general de los instrumentos negociales, habrá que convenir que un Acuerdo o Pacto en cuya virtud se aumente el número de delegados sindicales a determinadas secciones sindicales y no a todas -0 , al menos, no por igual-, constituye una norma jurídica que establece discriminaciones por razones de adhesión a un sindicato o al ejercicio, en general, de actividades sindicales, lo que, en los términos del artículo 12 de la LOLS, debe comportar su nulidad y carencia de efectos. Además, debe tenerse en cuenta que el artículo 10.2 de la LOLS atribuye el mismo número de delegados a todas las secciones con derecho a los mismos, siempre que en su constitución hayan utilizado la misma unidad de referencia. Por consiguiente, cabe considerar de necesaria observancia no sólo el número de delegados sindicales establecido en la LOLS sino también el criterio legal de igualdad entre secciones sindicales a la hora de atribuirles un número mayor de representantes. En todo caso, no es posible ofrecer una respuesta generalizada sobre la antisindicalidad de las cláusulas convencionales que establecen un número adicional y diferenciado de delegados sindicales entre las diferentes secciones sindicales, sino que habrá que realizar una valoración de cada caso concreto en función de las circunstancias y de las consecuencias de tales concesiones diferenciadas. Téngase en cuenta que la utilización por las partes negociadoras de un mismo módulo de cuantificación para determinar el número de delegados sindicales puede conducir a resultados distintos para las diferentes secciones sindicales. A este respecto, el principio general que podría establecerse es que tal diferenciación ha de tener una justificación objetiva y razonable y que, en todo caso, no puede representar una desincentivación tal de la afiliación a los sindicatos que no disfrutan de las mejoras pactadas que

89 En sentido contrario se expresa P. Gómez CABAllero, Los Derechos Colectivos..., cit., p. 230.

La STSJ de la Comunidad Valenciana de 12 de enero de 2000 (RJCA/2352), al enjuiciar el artículo 59 del Acuerdo del Ayuntamiento de Crespins de fecha de 19 de diciembre de 1997, aprobatorio de convenio de relaciones laborales del personal funcionario a su servicio, por el que se prevé la existencia de un Delegado Sindical a partir del 10\% de votos obtenidos en la elecciones sindicales o por demostrar tener el $10 \%$ de afiliados sobre el total de la plantilla cuyas cuotas sindicales se descuentan en nómina, afirma lo siguiente: «el art. 59 infringe el art. 10 de la Ley 11/1985, de 2 de agosto y 11.d) de la Ley 9/1987, en cuanto excede la previsión de éste sobre determinación del número de Delegados Sindicales, la cual se fija en función de que se haya obtenido o no el $10 \%$ de los votos en la elección del Comité de Empresa o al Órgano de Representación de las Administraciones Públicas, de manera que no es ajustada la referencia que el artículo del Convenio analizado realiza a la demostración de poseer el 10\% del personal afiliado sobre el total de la plantilla». 
coaccione decididamente la libertad de elección sindical de los funcionarios públicos ${ }^{90}$.

$3^{\circ}$ ) En tema de derechos, garantías y facilidades de los delegados sindicales, el artículo 10.3 de la LOLS establece que éstos, «en el supuesto de que no formen parte del comité de empresa, tendrán las mismas garantías que las establecidas legalmente para los miembros de los comités de empresa o de los órganos de representación que se establezcan en las Administraciones Públicas, así como los siguientes derechos a salvo de lo que se pudiera establecer por convenio colectivo». El cuadro de derechos de la representación sindical establecido en este precepto es mínimo, pues lo que la remisión al convenio colectivo está permitiendo es la posibilidad de que, por tal vía, se amplíen los derechos legalmente reconocidos y no una restricción de los mismos. En cuanto a las garantías y facilidades de los delegados sindicales, la LOLS utiliza como punto de referencia las que vengan reconocidas a los miembros de las Juntas de Personal, esto es, procede a una equiparación a estos efectos entre los miembros de las Juntas de Personal y los delegados sindicales. Dado que el cuadro de garantías y facilidades establecido en el artículo 11 de la LORAP para los primeros es indisponible para la negociación colectiva, habría que entender que dicho cuadro tampoco puede ser mejorado o ampliado vía Acuerdo o Pacto respecto de los delegados sindicales ${ }^{91}$. Pudiendo abundar en esta interpreta-

\footnotetext{
${ }^{90}$ En este sentido, hay que traer a colación la STC 188/1995, de 18 de diciembre, que, al enjuiciar los criterios empleados por un Acuerdo para atribuir un mayor número de delegados sindicales (la condición o no de sindicato más representativo y la obtención o no de un mínimo del 10 por 100 de audiencia en los dos órganos de representación del personal funcionario y laboral del Ayuntamiento [Junta de Personal y Comité de Empresa] o tan sólo en uno de ellos), sostiene que «estas dos consideraciones (el papel de modulación de la figura de los delegados sindicales y el hecho de que la figura del delegado sindical imponga cargas al empleador) justifican que el aumento de Delegados sindicales no se haga indiferenciadamente para todas las Secciones Sindicales que sobrepasen determinados porcentajes de audiencia electoral, sino que se tenga también en cuenta el carácter más representativo o no del sindicato en cuestión y su presencia o no en los dos órganos de representación del personal». En palabras del Alto Tribunal «no resulta objetable que si un sindicato tiene presencia en los dos órganos de representación del personal (Junta de Personal y Comité de Empresa) cuente con un mayor número de Delegados sindicales que aquel otro que la tiene únicamente en uno solo de tales órganos, porque esto se apoya en un criterio objetivo y es además adecuado y proporcionado, en cuanto que los Delegados tienen que ejercer sus funciones $\{\ldots\}$ en un ámbito más amplio, lo que lleva normalmente aparejada una superior carga organizativa y de trabajo», como «lo demuestran en la práctica situaciones como la asistencia a las reuniones de los órganos de representación unitaria o electiva del personal (artículo 10.3.2 LOLS), ya sea a las de la Junta de Personal o bien, además, a las del Comité de Empresa».

91 En este sentido, la STSJ de Castilla-La Mancha de 15 de septiembre de 1999 (RJCA/3197) afirma lo siguiente: «Artículo 47, sindicatos o representantes de los sindicatos: Debe ser anulado en la previsión incondicionada de un crédito horario de 20 horas mensuales. El crédito está regulado por ley y es el que corresponda de acuerdo con el artículo 11.d) de la Ley 9/1987, de 12 de junio; el
} 
ción el último inciso del artículo 10.3 de la LOLS, según el cual la referencia que se hace a los convenios colectivos - «a salvo de lo que se pudiera establecer por convenio colectivo»- no se refiere a garantías y derechos de los delegados sindicales sino sólo a estos últimos.

\subsection{Materias relativas a la salud laboral}

El artículo 32.i) de la LORAP incluye en el contenido de la negociación colectiva «las medidas sobre salud laboral» ${ }^{92}$. Es más, las disposiciones de la Ley 31/1995, de 8 de noviembre, de Prevención de Riesgos Laborales (LPRL), tienen el carácter de normas mínimas mejorables por la negociación colectiva (art. 2.2). A mayor abundamiento, las que configuran el esquema organizativo de la representación especializada de los empleados públicos en materia preventiva constituyen normas dispositivas. En efecto, según el párrafo $3^{\circ}$ del artículo 35.4 de la LPRL, en el ámbito de las Administraciones Públicas podrá «acordarse que las competencias que esta Ley atribuye a éstos (los Delegados de Prevención) puedan ser ejercidas por órganos específicos ${ }^{93}$. El carácter dispositivo alcanza a la regu-

acuerdo no debe ni puede preverlo expresamente, pues aunque pudiera en hipótesis corresponder al crédito adecuado de acuerdo con el artículo mencionado y el número de funcionarios que posea la corporación, lo cierto es que tal número puede cambiar, o incluso cambiar la previsión legal, y en definitiva es materia indisponible por estar regulada por ley y no ser un mínimo mejorable» y «es por las mismas razones ilegal el apartado 3 del artículo 47, pues el plazo de mantenimiento de las garantías es de un año, y no de dos (artículo 11 de la Ley mencionada)». Por su parte, la sentencia de la Sala de lo Contencioso-Administrativo del Tribunal Superior de Justicia de la Comunidad Valenciana de 12 de enero de 2000 (RJCA/2352), al enjuiciar el art. 59 del Acuerdo del Ayuntamiento de Crespins de fecha de 19 de diciembre de 1997, aprobatorio de convenio de relaciones laborales del personal funcionario a su servicio, por el que se prevé que los Delegados Sindicales dispondrán de un máximo de 20 horas mensuales para la realización de sus funciones, afirma que tal previsión «contraviene el art. 11.d) de la Ley 9/1987, de 12 de junio, que fija 15 horas mensuales para Administraciones de hasta 100 funcionarios, estando previsto el de 20 horas para Administraciones de 101 a 250 funcionarios». En el mismo sentido, la STSJ de Extremadura de 18 de marzo de 2003 (JUR/123676).

${ }^{92}$ Sobre este particular véase, por todos, R. RoQuETA BuJ, «La aplicación de la Ley de Prevención de Riesgos Laborales en las Administraciones Públicas», TS, n. ${ }^{\circ} 73$, 1997, pp. 56 y ss., y «La participación de los empleados públicos de la Administración General del Estado en materia de prevención de riesgos laborales», $A A$, n. $^{\circ}$ 16, 2000, pp. 567 y ss.; y P. Gómez CABALlero, La participación de los Trabajadores y los Funcionarios en la Prevención de Riesgos Laborales, Sevilla, 2003, pp. 129 y ss.

Como subrayan la STSJ de la Comunidad Valenciana de 17 de febrero de 1999 (RJCA/490) y 12 de enero de 2000 (RJCA/2352), los acuerdos que prevén la comunicación a terceros del resultado de los reconocimientos médicos infringen el artículo 63 de la LFCE, en redacción dada por el artículo 3 de la Ley 3/1989.

${ }^{93}$ Cfr. Disposición Transitoria $1^{\text {a }}$ de la LPRL. 
lación en su conjunto, incluidos los elementos estructurales o definidores del modelo legal. De este modo, la Ley habilita a la negociación colectiva para romper las barreras del derecho de participación de los empleados públicos derivadas de su supeditación a los sistemas de representación unitaria.

\subsection{Materias relativas a la Seguridad Social y de índole asistencial}

La negociación colectiva no se centra exclusivamente en el ámbito estrictamente funcionarial, sino que se extiende también a las materias relativas a la Seguridad Social y de índole asistencial. En este sentido, el artículo 32 de la LORAP indica que también forman parte del contenido negocial las siguientes materias: «f) La determinación de las prestaciones y pensiones de las clases pasivas y, en general, todas aquellas materias que afecten, de algún modo, a la mejora de las condiciones de vida de los funcionarios jubilados $\{\ldots\}$ j) Todas aquellas materias que afecten, de algún modo, ...(a la) Seguridad Social $\{. .$.$\} cuya regulación$ exija norma con rango de ley. k) Las materias de índole $\{. .$.$\} asisten-$ cial...».

Los funcionarios públicos locales en la actualidad están integrados en el campo de aplicación del Régimen General de la Seguridad Social (RD 480/1993, de 2 de abril), que se rige por el Real Decreto Legislativo 1/1994, de 20 de junio, por el que se aprueba el Texto Refundido de la Ley General de la Seguridad Social. Pues bien, la Seguridad Social obligatoria no está atribuida a la competencia de las Corporaciones Locales, ya que la Disposición Adicional $3^{\mathrm{a}} .1$ de la Ley 11/1960, de 12 de mayo, sobre creación de la Mutualidad Nacional de Previsión de la Administración Local, redactada por la Disposición Adicional del TRRL establece terminantemente que éstas no podrán en lo sucesivo «adoptar, respecto al personal a su servicio que haya de tener el carácter de asegurado, acuerdo alguno en materia de reconocimiento de derechos pasivos ni modificar el régimen de éstos» ${ }^{94}$. A esta conclusión no se opone el que el artículo 32 de la LORAP incluya las materias relativas a la Seguridad Social entre las propias de la negociación colectiva, ya que, como subraya la STSJ de Castilla-La Mancha de 3 de marzo de 2001 (JUR/169797), la norma se refiere a la negociación en todas las Administraciones Públicas, siendo posible la negociación en el ámbito de la Administración del Estado, que dé como resultado

94 STSJ de Galicia de 9 de junio de 1999 (RJCA/1992). 
un compromiso del Gobierno para promover un cambio legal en la materia; pero ello no autoriza a las EELL a introducir directamente cambios a través de acuerdos con sus funcionarios, tal y como reitera la claridad del artículo 32.j) de la referida ley a este respecto.

En cuanto a la Seguridad Social complementaria, debe tenerse en cuenta que la Disposición Adicional $4^{\text {a }}$ de la Ley 11/1960, redactada por la Disposición Adicional del TRRL, en línea con lo dispuesto en la Disposición Adicional $48^{\mathrm{a}}$ de la Ley 46/1985, de 27 de diciembre, de Presupuestos Generales del Estado para 1986, establece que «las Corporaciones Locales no podrán en lo sucesivo conceder aportaciones, subvenciones o ayudas de cualquier género para fines de previsión de sus funcionarios» y que «serán nulos los créditos que se concedan con infracción de este precepto...». Por ello, no pueden pactar y establecer prestaciones paralelas y complementarias de las del régimen público de la Seguridad Social que les supongan cargas presupuestarias ${ }^{95}$, tales como beneficios económicos en los casos de gastos sanitarios no cubiertos por la Seguridad Social ${ }^{96}$, complementos de los subsidios por incapacidad temporal ${ }^{97}$, premios por jubilación ${ }^{98}$ o premios por jubilación voluntaria ${ }^{99}$, ni comprometerse a concertar y pagar una póliza de seguro en beneficio de sus funcionarios ${ }^{100}$,

${ }^{95}$ SSTS de 10 de febrero de 1997 (RJ/1409), 30 de junio de 1997 (RJ/6138) y 2 de marzo de 2004 (RJ/2406); y STSJ de la Comunidad Valenciana de 17 de enero de 1999 (RJCA/490). Hay que subrayar que muchas de las resoluciones judiciales que se citan a continuación fundamentan esta afirmación en el hecho de que los complementos de las prestaciones del régimen público de la Seguridad Social suponen unas remuneraciones en metálico o en especie distintas de las previstas en el artículo 23 de la LMRFP (arts. 93 LBRL y 153 TRRL), que, además, pueden conllevar incrementos del gasto público superior al legalmente previsto y autorizado en las Leyes de Presupuestos respecto de Capítulos como los retributivos (art. 154 TRRL).

${ }^{96}$ SSTSJ de Asturias de 19 de abril de 1999 (RJCA/961); y de la Comunidad Valenciana, de 12 de enero de 2000 (RJCA/2352).

${ }^{97}$ STS de 4 de diciembre de 1995 (RJ/1564); y SSTSJ de Cantabria, de 11 de octubre de 2001 (RJCA/1511) y 27 de febrero de 2002 (RJCA/515); y de Madrid, de 19 de noviembre de 2002 (JUR/144738, 2003). En sentido contrario, las SSTSJ de Cantabria de 8 de abril y 29 de julio de 2002 (RJCA/773 y 748).

${ }^{98}$ SSTSJ de Galicia, de 15 de abril de 1998 (RJCA/1708); de Asturias, de 18 de mayo de 1998 (RJCA/1758) y 19 de abril de 1999 (RJCA/961); y de Madrid, de 19 de noviembre de 2002 (JUR/144738, 2003).

99 SSTSJ de Andalucía, de 9 de junio de 1999 (RJCA/1466) y 7 de febrero de 2001 (JUR/298183); de Castilla-La Mancha, de 3 de marzo de 2001 (JUR/169797); de Cantabria, de 11 de octubre de 2001 (RJCA/1511); de Castilla-La Mancha, de 9 de enero de 2002 (JUR/95677); y de Extremadura, de 18 de marzo de 2003 (JUR/123676).

100 SSTSJ de Asturias, de 19 de abril de 1999 (RJCA/961); de Andalucía, de 9 de junio de 1999 (RJCA/1466); de Cantabria, de 11 de octubre de 2001 (RJCA/1511), 8 de abril de 2002 (RJCA/773) y 29 de julio de 2002 (RJCA/748); y de Madrid, de 26 de noviembre de 2002 (JUR/144862, 2003). 
o a constituir un fondo para conseguir importes mínimos por jubilación y viudedad $\mathrm{u}$ orfandad ${ }^{101}$. Afirmación que no queda desvirtuada por la Disposición Final $2^{\mathrm{a}}$ del Real Decreto Legislativo 1/2002, de 29 de noviembre, por el que se aprueba el Texto Refundido de la Ley de Regulación de los Planes y Fondos de Pensiones, pues aunque admite que las «Administraciones públicas, incluidas las Corporaciones Locales, las entidades, organismos de ellas dependientes y empresas participadas por las mismas», puedan «promover planes de pensiones de empleo y realizar aportaciones a los mismos, así como a contratos de seguros colectivos $\{\ldots\}$, con el fin de instrumentar los compromisos u obligaciones por pensiones vinculados a las contingencias del artículo 8.6 de esta Ley referidos a su personal funcionario o laboral o en relación de servicios regulada por normas administrativas estatutarias», mantiene la limitación de aportaciones antes señalada, en la medida que lo anterior se entiende «sin perjuicio de la correspondiente habilitación presupuestaria de que disponga cada entidad o empresa, así como de las posibles autorizaciones previas a las que pudiesen estar sometidas tales aportaciones tanto de carácter normativo como administrativo, para, en su caso, destinar recursos a la financiación e instrumentación de la previsión social complementaria del personal» ${ }^{102}$.

No obstante ello, existen excepciones a esta regla general, a saber:

a) El artículo 19.Tres de la Ley 61/2003, de 30 de diciembre, de Presupuestos Generales del Estado para el 2004, establece que «además del incremento general de retribuciones previsto en el apartado anterior, las Administraciones, entidades y sociedades a que se refiere el apartado Uno del presente artículo, podrán destinar hasta un 0,5 por 100 de la masa salarial a financiar las aportaciones a planes de pensiones de empleo o contratos de seguro colectivos que incluyan la cobertura de la contingencia de jubilación, para el personal incluido en sus ámbitos, de acuerdo con lo establecido en la disposición final segunda del Texto Refundido de la Ley de Regulación de los Planes y Fondos de Pensiones» ${ }^{103}$.

101 STSJ de Madrid de 26 de noviembre de 2002 (JUR/144862, 2003).

102 B. SuÁrez Corujo, Los planes de pensiones del sistema de empleo. Principios ordenadores, Valladolid, 2003, p. 578.

103 El artículo 19.Tres de la Ley 61/2003 señala, además, que «para el cálculo del límite de la aportación total en el año 2004, se aplicará el porcentaje sobre el gasto correspondiente al conjunto de las retribuciones devengadas por el personal funcionario en los siguientes conceptos retributivos: retribuciones básicas, complemento de destino, complemento específico y complemento de productividad o conceptos análogos, y sobre la masa salarial correspondiente al personal sometido a la legislación laboral definida en el artículo 22.Uno de esta Ley, sin computar a estos efectos los gastos de acción social» y que «la asignación individual de las aportaciones correspondientes al personal funcionario y estatutario se determinará en relación con el grupo de clasificación al que perte- 
b) La Disposición Adicional $21^{\text {a }}$ de la LMRFP, adicionada por la Ley 22/1993, de 29 de diciembre, en línea con lo dispuesto en el artículo 34.2 de la misma ley respecto de los funcionarios públicos de la Administración del Estado ${ }^{104}$, establece que «las Comunidades Autónomas y las Corporaciones Locales, de acuerdo con su capacidad de autoorganización, podrán adoptar, además de Planes de Empleo, otros sistemas de racionalización de los recursos humanos, mediante programas adaptados a sus especificidades, que podrán incluir todas o alguna de las medidas mencionadas en los apartados 2 y 3 del artículo 18 de la presente Ley, así como incentivos a la excedencia voluntaria y a la jubilación anticipada». Ahora bien, los incentivos a la jubilación anticipada exigen la adopción por la Corporación Local de un sistema de racionalización de los recursos humanos, mediante programas adaptados a sus especificidades, de suerte que la negociación colectiva no puede preverlos con carácter general ante cualquier decisión de jubilación voluntaria anticipada ${ }^{105}$.

Por último, debe tenerse en cuenta que las materias de índole «asistencial» son susceptibles de negociación [art. 32.k) LORAP]. De este modo, la negociación colectiva puede prever ayudas por natalidad, guarderías, hijos menores de 18 años o disminuidos físicos o psíquicos, estudios universitarios para hijos mayores de 18 años o cónyuge, actividades culturales, deportivas o recreativas,... etc. Estas ayudas no tienen el carácter de retribuciones distintas de las previstas en el artículo 23 de la LMRFP ni de prestaciones complementarias de las del régimen público de la Seguridad Social y, por consiguiente, no entrañan vulneración del artículo 153 del TRRL y de la Disposición Adicional $4^{\mathrm{a}}$ de la Ley 11/1960 ${ }^{106}$. Las mismas constituyen ayudas incluidas dentro de la política social de las EE.LL con sus empleados ${ }^{107}$, que, al margen de la posible actuación de la correspondiente Comunidad Autó-

\footnotetext{
nezcan y con su antigüedad, de acuerdo a lo establecido en cada plan de pensiones o contrato de seguro». Por último, aclara que «las cantidades destinadas a financiar aportaciones a planes de pensiones o contratos de seguro, conforme a lo previsto en este apartado, tendrán a todos los efectos la consideración de retribución diferida».

104 Cfr. STSJ de Castilla-La Mancha de 3 de marzo de 2001 (JUR/169797).

105 Cfr. SSTSJ de Cantabria de 11 de octubre de 2001 (RJCA/1511), 8 de abril de 2002 (RJCA/773) y 6 de junio de 2003 (RJCA/809).

106 Cfr. STS de 15 de diciembre de 2003 (RJ/9011). En sentido contrario, las SSTSJ de Galicia, de 15 de abril de 1998 (RJCA/1708); de Asturias, de 18 de mayo de 1998 (RJCA/1758) y 19 de abril de 1999 (RJCA/961); de Andalucía, de 9 de junio de 1999 (RJCA/1466); y de Madrid, de 19 de noviembre de 2002 (JUR/144738, 2003).

107 En este sentido, las SSTSJ de Cantabria de 11 de octubre de 2001 (RJCA/1511), 27 de octubre de 2002 (RJCA/515), 8 de abril de 2002 (RJCA/773) y 29 de julio de 2002 (RJCA/748); y P.A. MARTíN PÉREZ, «La negociación colectiva...», cit., p. 1070.
} 
EL CONTENIDO DE LA NEGOCIACIÓN COLECTIVA DE LOS FUNCIONARIOS PÚBLICOS...

noma al legislar sobre la materia, encuentran su fundamento en el artículo 67.1 de la LFCE, a cuyo tenor «el Estado facilitará a sus funcionarios adecuada asistencia social, fomentando la construcción de viviendas, residencias de verano, instalaciones deportivas, instituciones educativas, sociales, cooperativas y recreativas y cuanto contribuya al mejoramiento de su nivel de vida, condiciones de trabajo y formación profesional y social» ${ }^{108}$. Además, no teniendo tales ayudas la condición de retribuciones, no están sujetas a los límites al incremento de las retribuciones o gastos de personal de las EELL previsto en la sucesivas Leyes de Presupuestos Generales del Estado $^{109}$. Por el contrario, los préstamos a fondo perdido o a bajo interés previstos en la negociación colectiva, salvo que se probase el fin social del destino de estas ventajas, vulneran el artículo 153 del TRRL, en relación con el artículo 23 de la LMRFP, en cuanto a las prohibiciónes para los funcionarios locales de participar en la distribución de fondos de ninguna clase y recibir remuneraciones distintas a las comprendidas en la antecitada Ley ${ }^{110}$.

\section{A modo de conclusión}

A la vista de lo expuesto, es evidente que el ámbito competencial de la autonomía colectiva local es reducido y residual. En este sentido, era muy ilustrativa la Disposición adicional 1. . Tres del Anteproyecto de Ley Reguladora del Estatuto de la Función Pública $(\mathrm{EBFP})^{111}$, al establecer que en las

\footnotetext{
108 Además, la Disposición Adicional 11 $1^{\text {a }}$ de la LMRFP establece que «las distintas Administraciones Públicas fomentarán la creación y desarrollo de servicios destinados al cuidado de los niños con el fin de facilitar el mejor desempeño de la función pública».

109 En este sentido, las SSTSJ de Cantabria de 11 de octubre de 2001 (RJCA/1511), 27 de octubre de 2002 (RJCA/515), 8 de abril de 2002 (RJCA/773) y 29 de julio de 2002 (RJCA/748).

110 En este sentido, la STSJ de Asturias de 19 de abril de 1999 (RJCA/961) y la STSJ de Madrid de 26 de noviembre de 2002 (JUR/144862). En sentido contrario, la STSJ de Cantabria de 11 de octubre de 2001 (RJCA/1511).

${ }^{111}$ El EBFP tenía su origen en el acuerdo alcanzado el 10 de febrero de 1998 en la Mesa general de negociación, tras un largo proceso de negociación entre la Administración del Estado, las Comunidades Autónomas y las Entidades Locales, de una parte, y los sindicatos, de otra. Sobre el alcance de las reformas que dicho EBFP proyectaba introducir en la materia que nos ocupa ver R. CATALA POLO, «El régimen jurídico de los empleados en los sistemas privados de gestión de los servicios públicos. Aproximación de regímenes en la Administración General del Estado», DA, n. ${ }^{\circ} 243$, 1995, pp. 128-129; G.P. RoJAS RIvERO, «Notas sobre la negociación colectiva en el Anteproyecto Básico de la Función Pública», RDS, n. ${ }^{\circ}$, 1998, pp. 233 y ss.; R. ROQUETA BUJ, «La negociación colectiva en el proyecto de estatuto básico de la función pública», $A L$, n. $^{\circ} 33,1998$, pp. 613 y ss.; y I. MARín ALONSO, «Problemática de la negociación colectiva funcionarial en el anteproyecto de estatuto básico de la función pública», Estudios Financieros, Revista de Trabajo y Seguridad Social, n. ${ }^{\circ}$ 193, 1999, pp. 3 y ss., y La negociación colectiva conjunta del personal laboral y funcionarial en la Administración Pública. Los acuerdos mixtos, Granada, 1999, pp. 3 y ss. Por lo demás, el borrador del EBFP que se maneja es el de 25 de marzo de 1998.
} 
Mesas generales de negociación de las EELL se podían negociar «la aplicación del incremento de las retribuciones complementarias, dentro de los límites previstos en la Ley de Presupuestos Generales del Estado de cada año» y «las materias de promoción, carrera profesional y condiciones de trabajo en los aspectos no regulados por normas de obligado cumplimiento».

Ante esta situación, los funcionarios públicos locales pueden tener la impresión de que la Ley no les garantiza su derecho a negociar sus condiciones de trabajo, pues éstas, en sus aspectos fundamentales, vienen predeterminadas por las Mesas generales de negociación de la Administración del Estado y de las CCAA, en las que no participan sus representantes. Para dar plena satisfacción al derecho de negociación colectiva de estos funcionarios, cabe proponer dos soluciones. Por un lado, extender también al ámbito de la función pública local la medida de la representatividad sindical que da paso a la legitimación para participar en tales Mesas de negociación cuando éstas establezcan normas de obligado cumplimiento en el ámbito de las EELL. De aceptarse este planteamiento, habría que distinguir una diversidad de sindicatos en el seno de las Mesas generales de negociación de la Administración del Estado y de las CCAA, en función de cual fuera el contenido de los Acuerdos y Pactos, lo que podría generar una gran complejidad. Sin embargo, sería la única solución que garantizaría la suficiencia representativa de la representación sindical en el ámbito al que se refieren las negociaciones, unas veces la función pública estatal o autonómica y otras el conjunto de la función pública. Por otro lado, cabe plantear la posibilidad de constituir Mesas «Inter-Administraciones» que abarcasen las tres AAPP - estatal, autonómica y local- u otras más limitadas, como podrían ser las que comprendieran una Comunidad Autónoma y las EELL ubicadas en el respectivo ámbito autonómico. Este tipo de mesas negociadoras, en las que, del lado de los funcionarios, habrían de participar los sindicatos más representativos y los simplemente representativos en el conjunto de las AAPP intervinientes en la negociación colectiva conjunta, permitirían a los funcionarios públicos locales participar en la determinación de todas sus condiciones de trabajo, al tiempo que permitirían armonizar la actividad negocial desarrollada por unas Mesas generales que tienen competencias concurrentes sobre las mismas materias. En esta línea, el artículo 92 del EBFP preveía la constitución de una «Mesa General de Negociación de todas las Administraciones Públicas», que se reservaba para los temas básicos y los de carácter general relacionados con sectores específicos de la función pública ${ }^{112}$. Previsión que, a juicio del Consejo de 112 Para una mayor información sobre este tema véase R. ROQUETA BUJ, «La negociación colectiva
en el proyecto...», cit., pp. 618 y ss. 
Estado, ofrecía «la ventaja innegable de establecer interlocutores aptos y plurales en relación a materias de trascendencia general». 